\title{
A matter of state: diversity in oligodendrocyte lineage cells
}

Yasmine Kamen ${ }^{1}$, Helena Pivonkova ${ }^{1}$, Kimberley A Evans ${ }^{1}$, and Ragnhildur T Káradóttir ${ }^{1,2}$

1. Wellcome - Medical Research Council Cambridge Stem Cell Institute \& Department of Veterinary Medicine, University of Cambridge, Cambridge, United Kingdom

2. Department of Physiology, BioMedical Center, Faculty of Medicine, University of Iceland, Reykjavik, Iceland

\section{Correspondence:}

Ragnhildur T. Káradóttir, PhD

Wellcome - MRC Cambridge Stem Cell Institute

University of Cambridge

Jeffrey Cheah Biomedical Centre

Puddicombe Way

Cambridge Biomedical Campus

Cambridge

CB2 A0W

email: rk385@cam.ac.uk 


\begin{abstract}
Oligodendrocyte precursor cells (OPCs) give rise to oligodendrocytes which myelinate axons in the central nervous system (CNS). Although classically thought to be a homogeneous population, OPCs are reported to have different developmental origins and display regional and temporal diversity in their transcriptome, response to growth factors, and physiological properties. Similarly, evidence is accumulating that myelinating oligodendrocytes display transcriptional heterogeneity. Analysing this reported heterogeneity suggests that OPCs, and perhaps also myelinating oligodendrocytes, may exist in different functional cell states. Here, we review the evidence indicating that OPCs and oligodendrocytes are diverse, and we discuss the implications of functional OPC states for myelination in the adult brain and for myelin repair.
\end{abstract}

\title{
Introduction
}

Myelin is a lipid-rich membrane compactly wrapped around axons that allows for rapid electrical conduction and input synchronization (Pajevic and others 2014). The importance of myelin becomes clear with the severe motor and cognitive symptoms observed in dysmyelinating disorders such as multiple sclerosis or leukodystrophies. In the central nervous system (CNS), oligodendrocytes produce myelin and provide metabolic support to the axons through the myelin sheath (Nave 2010). During development, oligodendrocytes arise from oligodendrocyte precursor cells (OPCs), and this capacity for differentiation continues into adulthood. However, in the adult, OPCs differentiate at a much lower rate than in development, making their abundance and even distribution in the adult brain enigmatic (Dawson and others 2003; Rivers and others 2008). Thus, it has been postulated that they are a unique cell type, the fourth glial cell, with functions beyond that of oligodendrocyte precursors, including interacting with the vasculature, modulating neuroinflammation and modulating neuronal synaptic signalling (Pepper and others 2018). However, the clearest role of adult OPCs remains differentiating into myelinating oligodendrocytes, which is critical for both myelin repair and learning (Tripathi and others 2010; McKenzie and others 2014; Pan and others 2020; Steadman and others 2020; Wang and others 2020). Both OPCs and oligodendrocytes express several ion channels and neurotransmitter receptors (Larson and others 2016; Marinelli and others 2016), making them sensitive to neuronal activity, which has been shown to modulate OPC proliferation and differentiation and 
oligodendrocyte myelination, and may therefore underlie learning-evoked myelination (Barres and Raff 1993; Gibson and others 2014; Mitew and others 2018). However, emerging evidence suggests that OPCs and oligodendrocytes may exhibit diversity in their sensitivity to neuronal activity, and other regulatory cues, which may have implications for our understanding of myelin repair and learning. Thus, here we review the evidence for OPC and oligodendrocyte diversity, propose that this evidence points to functional cell states, and examine the implications of OPC states for myelin repair and adult myelination.

\section{Oligodendrocyte precursor cell diversity}

OPCs are typically identified by morphology, a combination of antigens, and specific membrane properties (Figure 1). Early work discovered that these cells are labelled by antibodies against PDGFR $\alpha$ and NG2 (Nishiyama and others 1996). OPCs are also positive for OLIG2 and SOX10, two common markers for oligodendrocyte lineage cells. Electrophysiological studies defined OPCs as cells with fast tetrodotoxin-sensitive voltage-gated sodium channels, outwardly rectifying fast and delayed voltage-gated potassium channels, and lacking the tail currents typical of differentiated oligodendrocytes (Figure 1) (Sontheimer and others 1989; Berger and others 1991; Kettenmann and others 1991; Agathou and Káradóttir 2019). Further, OPCs were found to express AMPA/kainate receptors, and some express NMDA receptors, yet their utility as defining features remains unclear (Barres and others 1990; Berger and others 1992; Wang and others 1996; Karadottir and others 2005; De Biase and others 2010; Spitzer and others 2019). Therefore, antigens remain the gold standard by which to identify OPCs.

An increasing body of literature suggests that OPCs are diverse at the transcriptomic and functional level. This diversity may stem from the generation of OPCs in three spatially and temporally segregated developmental waves (Kessaris and others 2006). Using a Cre-lox approach, OPCs derived from these three waves can initially be identified by different transcription factors (first wave: $N k x 2.1$; second wave: Gsh2; third wave: $E m x 1$ ), although they are all positive for NG2 and PDGFR $\alpha$ and are physiologically, transcriptionally and functionally homogeneous (Kessaris and others 2006; Psachoulia and others 2009; Tripathi and others 2011; Marques and others 2018). Intriguingly, RNA from the transcription factors corresponding to the second and third waves can 
still be found postnatally in cortical OPCs (Zhang and others 2014; Marques and others 2018; Spitzer and others 2019). Nevertheless, both temporal and regional heterogeneity is observed in the OPC transcriptome (Lin and others 2009; Marques and others 2016; Marques and others 2018; Neumann and others 2019; Spitzer and others 2019; Ximerakis and others 2019; Marisca and others 2020), and the OPC proteome alters with age (de la Fuente and others 2020). Numerous studies also report diversity in OPC bioelectrical properties and neurotransmitter receptors (Blankenfeld and others 1992; Borges and others 1995; Rogers and others 2001; Chittajallu and others 2004; Ziskin and others 2007; Karadottir and others 2008; Karram and others 2008; VélezFort and others 2009; Vélez-Fort and others 2010; Maldonado and others 2013; Balia and others 2015; Moshrefi-Ravasdjani and others 2017; Marques and others 2018; Spitzer and others 2019), although this is disputed (De Biase and others 2010; Kukley and others 2010; Clarke and others 2012). Recently, we found that while OPCs appear in the forebrain as a homogeneous population lacking ion channels and glutamate receptors, they gradually acquire these with age, at different rates (Figure 2), and become physiologically heterogeneous between and within postnatal brain regions (Spitzer and others 2019), which may partially explain previous differing observations.

A small number of antigens including PLP, ASCL1, BCAS1 or GPR17 label subpopulations of OPCs, although their relation to the transcriptome or physiology is unclear (Mallon and others 2002; Parras and others 2007; Boda and others 2011; Fard and others 2017). Nonetheless, functional differences are described between OPCs that are antigenically indistinguishable. Proliferation and differentiation rates are lower in aged versus neonatal OPCs, and higher in white matter than grey matter OPCs (Wolswijk and Noble 1989; Shi and others 1998; Rivers and others 2008; Lin and others 2009; Psachoulia and others 2009; Clarke and others 2012; Viganò and others 2013; Young and others 2013; Moshrefi-Ravasdjani and others 2017; Spitzer and others 2019). These differences may partially be explained by the differential responses to growth factors and cytokines that occur with ageing and between brain regions (Chan and others 1990; Mason and Goldman 2002; Lin and others 2009; Hill and others 2013; Lentferink and others 2018; Neumann and others 2019).

These data indicate that OPCs are a diverse population. It is currently debated whether this diversity represents heterogeneity or cell plasticity (see reviews by Dimou and Simons 2017, and 
Foerster and others 2019). To define heterogeneity, we can look beyond OPCs, for example to GABAergic interneurons. These are a group of heterogeneous cells, each with a distinct subtype defined by a specific morphology, antigen(s), transcriptome, physiology, connectivity, and therefore, function (Lim and others 2018). This definition is difficult to apply to OPCs, as their diversity is poorly understood, and it is unclear how the observed range of transcriptomic, physiological, antigenic and functional properties relate to each other. Further, age-driven changes in the same NG2/PDGFR $\alpha$ positive population suggest a more dynamic system. In fact, transplantation studies indicate that OPC diversity is not solely determined by specific regional subtypes, as for GABAergic neurons, nor is it determined solely by the environment (Viganò and others 2013). These studies indicate that OPC diversity is more complex, and may not be fully explained by either distinct cell subtypes (i.e. true cell heterogeneity) or exclusive environmental regulation (i.e. where all cells, regardless of origin, exhibit the same phenotype when exposed to the same environment) but may rather be explained by a dynamic mixture of the two. In cell biology, it is known that often the same cell population, with a stable cell identity, can exist in multiple states and thus the same cell can exhibit different phenotypes, which may be associated with a molecular profile and function, that often depend on external cues (Morris 2019). Drawing from other fields such as stem cell biology, cancer, and immunology, we propose that OPCs can be found in the following functional states: naïve, migratory, highly proliferative, primed, quiescent, and senescent (Figure 3).

\section{Functional states}

\section{The naïve cell state}

A naïve cell state is a state where a cell is unconditioned or unstimulated by environmental factors that induce it to a specific path or function - a blank slate. The naïve state can be identified by a distinct molecular signature. Do OPCs, which are often thought to be homogeneous, exhibit a naïve cell state, as is common amongst progenitors, stem cells and other cell types with specific functional states? To determine the naïve state, it is best to examine early development, specifically when the cells are first born or appear. OPCs first appear in the medial ganglionic eminence and anterior entopeduncular area of the forebrain at E12.5 and distribute throughout the forebrain. Transcriptional studies and functional single-cell electrophysiological studies show that these early 
born OPCs are distinct from cells found later in development. PDGFR $\alpha$ positive E13 cells express lower transcript levels of genes associated with oligodendrocyte differentiation, growth factor binding, ion channels, glutamate receptors, and synaptic activity compared to postnatal OPCs, but have a higher expression of genes associated with cell cycling, neural progenitors, transcription factor activity, and the cytoskeleton (Marques and others 2018). These findings are reproduced in human foetal tissue, where a distinct population of PDGFR $\alpha$ positive cells was identified (Huang and others 2020; Perlman and others 2020). This population expresses a number of neural progenitor genes, and is marked by EGFR expression, which is also highly expressed in E13 murine PDGFR $\alpha$ positive cells (Marques and others 2018; Huang and others 2020). At a functional level, we found that NG2 positive E13 cells lack sodium and potassium voltage-gated ion channels, as well as glutamate receptors, which are classical hallmarks of postnatal OPCs (Figure 2) (Spitzer and others 2019). Thus, low levels of growth factor or cytokine receptors, and the absence of ion channels and glutamate receptors suggest that these E13 OPCs may lack the apparatus to respond to extracellular cues driving proliferation or differentiation, such as growth factor signalling or neuronal activity, and that this distinct molecular and physiological signature may define the naïve OPC state (Figure 3).

Naïve OPCs (lacking glutamate receptors and voltage-gated ion channels) are observed at all ages and in all brain regions; however, they are a minority of OPCs in postnatal timepoints (Figure 4) (Spitzer and others 2019). Thus, as these cells are mostly restricted to embryonic timepoints, this profile may be characteristic of OPCs generated in the first developmental wave and may therefore represent a cell subtype rather than a cell state (Kessaris and others 2006). However, analysis of the transcriptome and physiology of OPCs derived from the first and third waves shows that they do not differ postnatally (Marques and others 2018). In addition, OPCs derived from the first wave account for approximately 95\% of callosal OPCs at P0 (Kessaris and others 2006), while naïve OPCs represent less than 1\% (Spitzer and others 2019), and cannot be detected by sequencing in neonates (perhaps due to differing sensitivity of RNA sequencing and single-cell electrophysiological recordings) (Marques and others 2018). Further, although OPCs derived from the first wave disappear from the adult cortex and corpus callosum, naïve OPCs are occasionally observed in these and other regions; in fact, postnatally, the highest proportion of these OPCs is found in the dorsal subventricular zone (Spitzer and others 2019) where OPCs from the first wave 
or Nkx2.1 progenitors are hardly detected (Kessaris and others 2006; Young and others 2007). These data suggest that while all E13 OPCs are naïve, naïve OPCs persist in the postnatal brain, possess a unique transcriptional and physiological profile, and may represent a cell state rather than origin-derived heterogeneity.

\section{The migratory cell state}

A migratory cell state is a state of rapid and substantial migration, often occurring when a cell population generated in a defined domain migrates to populate a larger region. The migratory state can be difficult to distinguish from a highly proliferative state, as migration and population expansion often occur simultaneously. However, a migratory state would exhibit a specific molecular signature characterised by an upregulation of migratory and cytoskeletal genes. During development, OPCs initially appear in the ventral forebrain and migrate into the dorsal forebrain, and in adults, OPCs rapidly migrate into demyelinating or acute lesions, suggesting that they may exhibit a migratory state (Franklin and others 1997; Dimou and Gallo 2015). Thus, examining OPCs immediately after injury or while cells generated ventrally migrate into the dorsal brain may allow us to examine the potential of a migratory state.

While limited data exist, OPCs at E16 express high levels of migration, axon guidance, and cytoskeletal genes (Spitzer and others 2019). Further, single-cell sequencing of a small number of E17.5 PDGFR $\alpha$ positive cells indicates that they begin to exhibit diversity in their transcriptome, clustering with both E13 and neonatal OPCs (Marques and others 2018). Electrophysiological studies find that voltage-gated potassium channels and AMPA/kainate receptors are first detected in E18 OPCs (Figure 2D), and are unlikely to reflect the establishment of the second developmental wave, which does not differ physiologically from the other waves (Tripathi and others 2011; Spitzer and others 2019). Both voltage-gated potassium channels and AMPA/kainate signalling promote OPC migration (Wang and others 1996; Gudz and others 2006; Tiwari-Woodruff and others 2006; Harlow and others 2015). Notably, during the recruitment phase (OPC migration and proliferation) following a toxin-induced demyelinating lesion, only AMPA/kainate currents are detected (Gautier and others 2015). Taken together, these data suggest that OPCs may exhibit a migratory state, marked by a distinct transcriptome and physiology (Figure 3). However, 
potassium channels and AMPA/kainate signalling are also thought to regulate OPC proliferation (Yuan and others 1998; Ghiani and others 1999; Chittajallu and others 2002; Vautier and others 2004; Fannon and others 2015), and thus, whether this distinct transcriptional and physiological profile represents a distinct migratory state, or rather a transition point between the naïve and highly proliferative states remains to be determined.

\section{The highly proliferative cell state}

In proliferative cells, a rapid proliferation state differs from slower baseline growth, and is a state of rapid cell growth, occurring when expansion of the cell population is needed. This state is transcriptionally and functionally different from other states of that same cell. The ability to proliferate is one of the essential characteristics of OPCs. However, like most stem cells, the proliferation rate varies in OPCs, with rapid OPC proliferation occurring after acute or demyelinating injuries in the adult (Levine and Reynolds 1999; Dimou and Gallo 2015) or regional differences during normal brain homeostasis, indicating that OPCs may exhibit a proliferative state, where they show rapid turnover. The strongest evidence comes from studies comparing different brain regions, where white matter OPCs cycle faster than grey matter OPCs, and exhibit a stronger response to the mitogen PDGF (Psachoulia and others 2009; Clarke and others 2012; Hill and others 2013; Young and others 2013; Spitzer and others 2019), although Viganò and others (2013) report no differences in proliferation rate between grey and white matter OPCs following transplantation. With age however, proliferation dramatically decreases as a result of cell cycle time lengthening (Wolswijk and Noble 1989; Shi and others 1998; Lin and others 2009; Psachoulia and others 2009; Young and others 2013; Marques and others 2016; MoshrefiRavasdjani and others 2017; Spitzer and others 2019). Thus, whether OPCs exhibit a proliferative cell state, and what its hallmarks may be, can be determined during early development, or following injury to the CNS, when it is known that the OPC population is expanding.

Transcriptional studies reveal a distinct population of cycling OPCs, mostly detected in neonates, during the peak of proliferation, and enriched in cell cycle and proliferation genes (Marques and others 2018). Similarly, a cluster of highly proliferative OPCs is detected in human foetal tissue, coinciding with population expansion (Huang and others 2020). These data indicate that while 
OPCs cycle throughout life, a population of highly proliferative cells congregates during early development (Young and others 2013; Marques and others 2018; Spitzer and others 2019; Ximerakis and others 2019; Huang and others 2020). Electrophysiological studies show that at the same timepoint, the density of voltage-gated sodium channels peaks in NG2 positive cells (Figure 2A), and recordings in KI67-RFP or FUCCI2a reporter mice (which mark actively cycling cells) show that proliferating OPCs have a higher density of voltage-gated sodium channels (Spitzer and others 2019). Further, three days after global cerebral ischemia, at the peak of proliferation, hippocampal OPCs increase their outward voltage-gated potassium channel densities (Pivonkova and others 2010). Thus, these data indicate that there is a highly proliferative population of PDGFR $\alpha$ and NG2 positive OPCs with a distinct transcriptomic and physiological profile, as well as a distinct function, suggesting that it is representative of a cell state (Figure 3).

How voltage-gated sodium channels may regulate OPC proliferation is unclear, but they have been implicated in the proliferation of cancer cell lines, retinal ganglion cell precursors, and astrocytes (Pereira and Araujo 1997; MacFarlane and Sontheimer 2000; Anderson and others 2003). In addition, depolarized cells proliferate more than hyperpolarized cells (Binggeli and Weinstein 1986), and sodium channels modulate the resting membrane potential in OPCs (Xie and others 2007). Further, cells with high sodium channel densities would have increased sensitivity to neuronal activity, which promotes proliferation (Barres and Raff 1993; Gibson and others 2014; Mitew and others 2018). However, increasing intracellular sodium with kainate or veratridine (which prevents voltage-gated sodium channel inactivation) decreases OPC proliferation by blocking outward potassium currents, which regulate cell cycle progression, and have been shown to be regulated by PDGF signalling (Knutson and others 1997; Ghiani and others 1999; Chittajallu and others 2002; Vautier and others 2004; Chittajallu and others 2005). Thus, rather than promote proliferation, the onset of high densities of sodium channels could in fact downregulate proliferation and promote transition into another cell state.

\section{The primed cell state}

A primed cell state is a state between cell growth and rapid effector function in which cells are primed/poised to differentiate. The primed cell state is achieved when cells are exposed to the 
more complex microenvironmental cues that initiate differentiation potential and is reflected by specific primed signatures. In the forebrain, the rate of myelination peaks in the first postnatal month, but varies between regions (Hamano and others 1998). In line with this, OPCs display temporal and regional differences in differentiation potential. For instance, white matter OPCs differentiate at a higher rate than grey matter OPCs and aged OPCs have reduced differentiation potential (Wolswijk and Noble 1989; Rivers and others 2008; Viganò and others 2013; Young and others 2013; Neumann and others 2019). Thus, analysing OPCs during the peak of myelination provides the potential to determine the OPC primed state.

Bulk sequencing OPCs during this timepoint shows that they upregulate genes involved in differentiation, signal transduction, synaptic signalling, ion transport, and glutamate receptors (Marques and others 2018; Spitzer and others 2019). Single-cell sequencing studies detect a population of neonatal OPCs distinct from cycling, embryonic and adult OPCs. This cluster is similar enough to the adult OPC cluster to likely represent a cell state rather than a cell type (Marques and others 2018). In human tissue, OPCs analysed during the peak of myelination upregulate genes related to cholesterol metabolism, cell adhesion and extracellular matrix composition, all essential markers of myelination, compared to adult OPCs, indicating that these OPCs are primed to differentiate and myelinate (Perlman and others 2020). Electrophysiological recordings from OPCs during the peak in differentiation and myelination show that the proportion of OPCs with NMDA receptors and the density of NMDA receptors are highest in this timepoint, alongside a high density of voltage-gated sodium channels, and are particularly high in the white matter, where myelination occurs at a higher rate (Spitzer and others 2019), and in demyelinating lesions at the time OPCs start to differentiate (Gautier and others 2015). Further, NMDA receptors are absent from aged OPCs, which have reduced differentiation potential (Figure 2). Since OPCs with NMDA receptors seem to be primed for differentiation, it could be proposed that they are early differentiated oligodendrocytes. However, the fact that these cells still proliferate argues more strongly for this being a specific OPC state (Spitzer and others 2019). Together, these data suggest that there may be a population of OPCs, identifiable by a transcriptional profile and NMDA receptor expression, that are in a primed state (Figure 3). As primed OPCs are still proliferative cells, they potentially can either undergo proliferation prior to differentiation or 
directly differentiate; current evidence supports both possibilities (Hughes and others 2013, Hill and others 2014; Bacmeister and others 2020).

In myelinating oligodendrocytes, NMDA receptor signalling is thought to regulate glucose import (Saab and others 2016). Perhaps primed OPCs upregulate NMDA receptors to provide energy in preparation for differentiation. Intriguingly, this cell population is marked by increased metabolic activity genes (Marques and others 2018; Spitzer and others 2019). Although NMDA receptor knockouts appear to have little effect on myelination (De Biase and others 2011; Guo and others 2012; Saab and others 2016), blocking NMDA signalling in the young adult prevents myelin regeneration after a toxin-induced demyelinating lesion (Lundgaard and others 2013). The discrepancies between the knockout and drug studies may stem from the fact that NMDA receptors are knocked out prior to their upregulation, preventing the switch to the activity- and NMDAdependent mode of myelination, as the switch is dependent on NMDA receptor activation (Lundgaard and others 2013). Nonetheless, the concomitance of NMDA receptor expression with the peak of myelination suggests that it may identify the primed state, although it is likely to be one of many markers for this cellular state.

\section{The quiescent cell state}

Quiescence is a state in which a cell reversibly enters G0 (or an extended G1), with the potential to re-enter the cell cycle upon stimulation. Most quiescent stem cells or progenitors share a common pattern of gene expression, including the downregulation of cell cycle and metabolic genes (Cheung and Rando 2013). Quiescence differs from senescence, where cells have irreversibly exited the cell cycle. To determine whether OPCs potentially show a quiescent cell state, we reviewed the literature on functional changes in OPCs with age, as in most other tissues the quiescent cell state is more common in older animals.

OPCs in the mature CNS are characterised by a decrease in proliferation as the cell cycle lengthens (Wolswijk and Noble 1989; Shi and others 1998; Rivers and others 2008; Lin and others 2009; Psachoulia and others 2009; Young and others 2013; Marques and others 2016; MoshrefiRavasdjani and others 2017; Spitzer and others 2019). Further, the transcriptome and proteome of 
aged OPCs show decreased cell cycle genes and proteins, decreased metabolic processes, and an increased quiescent signature (Cheung and Rando 2013; Neumann and others 2019; Spitzer and others 2019; de la Fuente and others 2020).

Quiescence is a reversible state. Are the changes in OPCs reversible? Following a demyelinating injury, adult OPCs revert to a neonatal-like transcriptome (Moyon and others 2015). In addition, single-cell sequencing showed that OPCs isolated from mice with experimental autoimmune encephalomyelitis (EAE), a mouse model of the inflammatory component of multiple sclerosis, clustered separately from OPCs isolated from control mice, and upregulated proliferation and differentiation genes, perhaps indicating a shift from the quiescent state to proliferative and primed states in response to inflammation (Falcão and others 2018). Surprisingly, sequencing also identified a population of immunocompetent OPCs, expressing MHC II proteins and capable of phagocytosis (Falcão and others 2018; Kirby and others 2019). These OPCs may perhaps be observed with ageing, as immune response related genes, including MHC II related genes, increase in nine month old mice along with quiescence genes (Spitzer and others 2019). However, the function of these immunocompetent OPCs is currently unknown. Further, quiescence can be induced in human foetal OPCs, indicating that human OPCs also likely exhibit a reversible quiescent state (Wang and others 2018).

With ageing, the physiological properties of OPCs are also altered. OPCs show decreased voltagegated sodium channel densities, and acquire a high resting potassium conductance, which is associated with G1, perhaps indicating that aged OPCs are entering an extended G1 (Maldonado and others 2013; Urrego and others 2014). Further, aged OPCs are characterised by the loss of NMDA receptors, and a high AMPA/kainate receptor density (Figures 2, 3) (Spitzer and others 2019). Of note, in this study, we applied kainate at a concentration that activates both AMPA and kainate receptors, and thus could not distinguish between the two; as kainate receptors have a higher single-channel conductance than AMPA receptors, the observed increase in AMPA/kainate receptor density could indicate a shift from AMPA to kainate signalling rather than an equivalent increase in receptor density, but this remains to be investigated. It is unclear why AMPA/kainate signalling increases with ageing, as some studies report that it blocks proliferation and differentiation (Yuan and others 1998; Fannon and others 2015), while constitutively knocking out 
AMPA receptors leads to myelination defects (Kougioumtzidou and others 2017). However, altering AMPA receptor subunits during the peak of myelination differentially affects proliferation and differentiation, confirming the importance of AMPA signalling in vivo, and indicating that dynamic changes in receptor function are likely to modulate OPC proliferation and differentiation, supporting the idea of OPC functional states (Chen and others 2018). In addition, while the density of ion channels and glutamate receptors alter with age, their transcript levels remain stable postnatally, enabling rapid protein expression and membrane insertion, suggesting that adult OPCs are in a reversible G0 state or extended G1 state, and thus, represent the quiescent OPC state (Spitzer and others 2019).

\section{The senescent cell state}

Senescence is a state in which a cell has irreversibly exited the cell cycle and permanently entered G0. The senescent and quiescent states can be difficult to distinguish transcriptionally, as several molecular markers are expressed in both states, although senescence does have some unique markers (Terzi and others 2016). Senescent cells accumulate with age, and thus, identifying the existence of a senescent OPC is best done in aged animals (Van Deursen 2014). We previously reported genes associated with senescence in nine month old OPCs; however, these genes are more likely to be associated with quiescence (Cheung and Rando 2013; Beerman and others 2014; Spitzer and others 2019). In addition, we did not detect any changes in the transcript levels of genes only associated with senescence (Terzi and others 2016; Spitzer and others 2019). Markers typically associated with senescent cells such as increased Cdkn2a or decreased ribosomal biosynthesis have only been detected in OPCs from 20 month old animals (Terzi and others 2016; Lessard and others 2018; Neumann and others 2019; Ximerakis and others 2019). Thus, with ageing, OPCs may enter a senescent state (Figure 3).

\section{OPC states}

Correlating data obtained from electrophysiology, transcriptomic and proteomic analyses, and cell function, we propose that OPCs can be found in different functional states. However, it is difficult to confirm that states identified by electrophysiology or sequencing are identical. For instance, 
while we detected changes in ion channels and glutamate receptors at a functional level, we could not detect these changes in the transcriptome, indicating that these cell states may not be detected by sequencing alone, or that additional markers are needed (Spitzer and others 2019). Further, it remains unclear whether the distinct profiles described above are transient or permanent. Our electrophysiological data suggest somewhat transient profiles, as we observe varying proportions of each state at different timepoints, and in different brain regions, following function (Figure 4). However, individual single-cell sequencing studies have mostly been restricted to two timepoints and may therefore not capture the full range of possible cell states, or the progression between states, although human sequencing data collected at multiple timepoints appear to recapitulate the electrophysiological functional states (Perlman and others 2020). Interpreting transplantation, injury and long-term imaging studies from the viewpoint of the aforementioned states, it appears that OPCs can transition between states when exposed to a different environment or changes in neuronal activity, but are rather stable in a specific state when undisturbed in young adult animals (Hughes and others 2013, Viganò and others 2013; Hill and others 2014; Marisca and others 2020). Nonetheless, until precise and cohesive physiological, transcriptomic, proteomic and epigenetic profiles are defined, and found to be transient or fixed, these data remain correlative. Importantly, this knowledge will provide mechanisms to directly address the constraints and the extent of OPC state transitions.

\section{Oligodendrocyte diversity}

Oligodendrocytes are a major cell population in the human CNS (Salvesen and others 2017; Perlman and others 2020). While morphological diversity in mature oligodendrocytes was described in the early twentieth century, these cells are generally described as a functionally homogeneous population (del Rio-Hortega 1928; Bakiri and others 2011; Chong and others 2012). However, some evidence indicates that oligodendrocytes may preferentially myelinate specific axonal tracts or respond differently to myelination cues, suggesting that they display functional heterogeneity (Tripathi and others 2011; Bechler and others 2015; Osanai and others 2017). Furthermore, single-cell sequencing of adult oligodendrocytes in the somatosensory cortex and hippocampus identified six differentiated oligodendrocyte states ranging from newly differentiated to terminally differentiated (Zeisel and others 2015). One intermediate state was found mostly in 
the somatosensory cortex, suggesting that it may represent a region-specific cell state, although it might also reflect the posterior-anterior progression of myelination (Flechsig 1901; Zeisel and others 2015). This finding was replicated in human tissue, where several mature oligodendrocyte states were identified (Jäkel and others 2019), although Perlman and others (2020) did not detect these subsets. Additional sequencing studies in multiple murine CNS regions identified six further states within the two myelinating and terminally differentiated states reported previously (Zeisel and others 2015; Marques and others 2016) (Figure 5), although these six states are not consistently detected between studies (Falcão and others 2018). The functional correlates of these states are unclear, but may represent different stages in myelination (Figure 6). For instance, clusters MOL14 are enriched in lipid biosynthesis and myelination genes, suggesting that they are actively myelinating (Marques and others 2016). However, within this group, individual clusters show varying levels of enrichment for lipid synthesis, perhaps indicating different stages in the myelination process. In addition, one cluster, MOL3, was also enriched in synaptic genes, perhaps indicating that it is altering myelin thickness in response to neuronal activity at the axo-myelinic synapse (Micu and others 2006; Gibson and others 2014; Mitew and others 2018), or searching for new active neurons to myelinate (Hines and others 2015; Mensch and others 2015; Bacmeister and others 2020). Intriguingly, MOL3 is increased following EAE induction, perhaps indicating a contribution of myelinating oligodendrocytes to remyelination (Falcão and others 2018; Bacmeister and others 2020). Clusters MOL5 and MOL6 are enriched in synapse, actin-binding and actin cytoskeleton reorganization genes but may be more mature, as they have lower expression of genes driving myelination, compared to MOL1-4 (Marques and others 2016). Based on these differentially expressed genes, it is possible to postulate that clusters MOL5-6 may indicate cells actively undergoing sheath elongation or retraction induced by neuronal activity, as actin turnover drives myelin growth, and calcium signalling regulates internode elongation or retraction; thus, these cells may be engaged in myelin remodelling (Nawaz and others 2015; Baraban and others 2018; Hughes and others 2018; Krasnow and others 2018; Bacmeister and others 2020). Whether these profiles represent different cell types or different cell states is still unclear; nonetheless, identifying the function associated with each profile, and whether this function is transient, which would be indicative of states, or permanent, which would indicate cell types, will provide a better understanding of oligodendrocyte diversity. This may be particularly important in the context of multiple sclerosis, as the proportion of cells in individual 
oligodendrocyte clusters is altered in both EAE and multiple sclerosis (Falcão and others 2018; Jäkel and others 2019, Schirmer and others 2019).

\section{Implications for myelination and myelin repair}

\section{Activity-dependent myelination and cell states}

Neuronal activity regulates OPC proliferation and differentiation, as well as myelination (Barres and Raff 1993; Gibson and others 2014; Mitew and others 2018), likely through neurotransmitter signalling, glutamate in particular, and growth factor signalling (Lundgaard and others 2013; Geraghty and others 2019, Swire and others 2019). However, in vitro, oligodendrocytes can myelinate inert fibres, indicating that myelination can proceed independent of activity (Lee and others 2012; Bechler and others 2015). We previously showed that there are two modes of myelination: a neuronal activity- and NMDA receptor-dependent mode, and an activityindependent mode. Activity-dependent release of neuregulin (NRG), or BDNF, and simultaneously glutamate, switches myelination from an activity-independent mode to an activitydependent mode, where the rate of myelination is increased. In the absence of NRG or BDNF, myelination proceeds independently of activity, but once the switch has occurred, blocking NMDA receptors prevents myelination (Lundgaard and others 2013). NRG or BDNF alongside glutamate released from active neurons increases NMDA receptor currents in OPCs and the proportion of cells with NMDA receptors, indicating that this switch to activity-dependent myelination may involve OPCs transitioning into a primed state (Figure 7; alternatively, NRG or BDNF may stimulate the generation of a new pool of primed OPCs). Indeed, primed OPCs exhibit high densities of NMDA receptors and voltage-gated sodium channels, and thus have a high sensitivity to neuronal activity, suggesting that they are the most likely state to be involved in activitydependent myelination.

However, this raises many questions. With age, primed OPCs are replaced by a population of quiescent cells. Nonetheless, low levels of cortical myelination continue throughout life, and myelination can be enhanced in aged mice by specific triggers such as sensory enrichment or learning (Hill and others 2018; Hughes and others 2018; Wang and others 2020). What happens to quiescent OPCs following these triggers? Does sensory enrichment or learning promote activity- 
dependent release of NRG or BDNF and promote a transition back into a primed state? Alternatively, myelination in aged mice could depend on already existing oligodendrocytes, although the sheer number of OPCs present in the CNS throughout adulthood suggests otherwise (Bacmeister and others 2020). And what of the naïve OPCs? Are they needed for activityindependent myelination during the early stages of development? If so, why does a small number remain in the postnatal brain? Do they represent a reserve pool of stem cells? Subventricular zone OPCs have been shown to migrate into the corpus callosum following toxin-induced demyelinating lesions (Menn and others 2006; Etxeberria and others 2010), indicating that this may be the case. Alternatively, are naïve OPCs simply an early stage in the lineage? If this were the case, all OPCs should be born as naïve, but this remains to be ascertained.

Importantly, other factors beyond NRG have been shown to regulate glutamate receptors and ion channels in OPCs (Gallo and others 1994; Chittajallu and others 2005; Zonouzi and others 2011), indicating that complex regulation is at play, and that a better understanding of OPC diversity, or functional states and their regulation, is key for our understanding of activity-dependent myelination.

\section{Myelin repair and cell states}

As developmental OPC cell states or diversity are recapitulated in demyelinating lesions undergoing regeneration (Gautier and others 2015; Moyon and others 2015; Falcão and others 2018), studying OPC diversity, or OPC functional states, may be critical for understanding disease progression and developing therapeutic approaches. For instance, OPCs in human chronic MS lesions were described as quiescent, as they fail to proliferate or differentiate (Wolswijk 1998). Given that the majority of OPCs become quiescent with age, it may be important to focus on this state, and examine if it can be pushed to a primed state to promote myelin repair. While a number of studies have identified compounds to promote remyelination in white matter demyelinating or inflammatory lesions (reviewed by Franklin and ffrench-Constant 2017), most studies focus on young animals. Nevertheless, some recent studies have shown that remyelination can be enhanced in aged animals by systemic rejuvenation, altering OPC sensitivity to the microenvironment, or compounds that act on OPCs and "rejuvenate" them (Ruckh and others 2012; Neumann and others 
2019; Segel and others 2019), indicating that changes occurring with ageing can be reversed. Recently, it was also shown that mature myelinating oligodendrocytes could contribute to remyelination (but see Neumann and others 2020), and sequencing mature oligodendrocytes in multiple sclerosis brains suggested that they had higher proportions of actively myelinating mature oligodendrocytes compared to control brains, indicating that injury may promote a shift to a more myelinating state to contribute to repair (Jäkel and others 2019; Yeung and others 2019; Bacmeister and others 2020). Identifying which OPC or mature oligodendrocyte states to target following injury may prove crucial to promote myelin regeneration.

\section{Conclusion}

Increasing evidence suggests that OPCs, and perhaps mature oligodendrocytes, are functionally diverse. The convergence of transcriptomic, proteomic and electrophysiological signatures with a specific function suggests that this diversity underlies cell states, rather than cell types. Nevertheless, these signatures could be interpreted to represent cell types, with specific OPC populations perhaps giving rise to specific oligodendrocyte populations. This is currently difficult to establish, given the different methodologies used to examine OPC and oligodendrocyte diversity. A more cohesive approach may provide more data supporting this hypothesis, but nonetheless, it remains unlikely, given the dynamic changes occurring in OPC properties with age, while all oligodendrocyte populations are detected in different age ranges, and the shifts in the transcriptome of oligodendrocyte lineage cells in disease. Whether this diversity underlies states or cell types will determine how oligodendrocyte lineage cells respond to the various cues driving lineage progression and myelination, and how these cues can be manipulated to promote myelin regeneration. Thus, a better understanding of OPC diversity and whether it represents cell types or functional states, and how these states might be regulated, will be crucial to provide insights into myelination and myelin repair.

\section{Acknowledgements}

We would like to thank our funders: the European Research Council (ERC: the European Union's Horizon 2020 research and innovation programme grant agreement No 771411; R.T.K., K.A.E.); 
the Wellcome (Studentship award 102160/Z/13/Z; Y.K., and Pathfinder Award 204488/Z/16/Z; R.T.K., H.P.); The Fonds de recherche du Québec-Santé (a scholarship, Y.K.); The Cambridge Commonwealth European \& International Trust (a scholarship, Y.K.); and the Lister Institute of Preventive Medicine (a research prize, R.T.K.). The funders had no role in decision to publish, or preparation of the manuscript.

\section{References}

Agathou S, Káradóttir RT. 2019. Whole-cell patch clamp recordings from oligodendrocyte lineage cells in brain slices. In: Lyons D and Kegel L (eds). Oligodendrocytes. Methods in Molecular Biology, vol. 1936. New York: Humana Press. pp. 141-168.

Anderson JD, Hansen TP, Lenkowski PW, Walls AM, Choudhury IM, Schenck HA, and others. 2003. Voltage-gated sodium channel blockers as cytostatic inhibitors of the androgenindependent prostate cancer cell line PC-3. Mol. Cancer Ther 2(11):1149-1154.

Bacmeister CM, Barr HJ, McClain CR, Thornton MA, Nettles D, Welle CG, and others. 2020. Motor learning promotes remyelination via new and surviving oligodendrocytes. Nat Neurosci 23(7):819-831.

Bakiri Y, Káradóttir R, Cossell L, Attwell D. 2011. Morphological and electrical properties of oligodendrocytes in the white matter of the corpus callosum and cerebellum. J Physiol 589(3):559-573.

Balia M, Vélez-Fort M, Passlick S, Schäfer C, Audinat E, Steinhäuser C, and others. 2015. Postnatal down-regulation of the GABAA Receptor $\gamma 2$ subunit in neocortical NG2 cells accompanies synaptic-to-extrasynaptic switch in the GABAergic transmission mode. Cereb Cortex 25(4):1114-1123.

Baraban M, Koudelka S, Lyons DA. 2018. Ca 2+ activity signatures of myelin sheath formation and growth in vivo. Nat Neurosci 21(1):19-23.

Barres BA, Koroshetz WJ, Swartz KJ, Chun LL, Corey DP. 1990. Ion channel expression by white matter glia: the O-2A glial progenitor cell. Neuron 4(4):507-524.

Barres BA, Raff MC. 1993. Proliferation of oligodendrocyte precursor cells depends on electrical activity in axons. Nature 361(6409):258-260.

Bechler ME, Byrne L, ffrench-Constant C. 2015. CNS Myelin Sheath Lengths Are an Intrinsic 
Property of Oligodendrocytes. Curr Biol 25(18):2411-2416.

Beerman I, Seita J, Inlay MA, Weissman IL, Rossi DJ. 2014. Quiescent Hematopoietic Stem

Cells Accumulate DNA Damage during Aging that Is Repaired upon Entry into Cell Cycle.

Cell Stem Cell 15(1):37-50.

Berger T, Schnitzer J, Kettenmann H. 1991. Developmental changes in the membrane current pattern, $\mathrm{K}+$ buffer capacity, and morphology of glial cells in the corpus callosum slice. $\mathrm{J}$ Neurosci 11(10):3008-3024.

Berger T, Walz W, Schnitzer J, Kettenmann H. 1992. GABA- and glutamate-activated currents in glial cells of the mouse corpus callosum slice. J Neurosci Res 31(1):21-27.

De Biase LM, Kang SH, Baxi EG, Fukaya M, Pucak ML, Mishina M, and others. 2011. NMDA receptor signaling in oligodendrocyte progenitors is not required for oligodendrogenesis and myelination. J Neurosci 31(35):12650-12662.

De Biase LM, Nishiyama A, Bergles DE. 2010. Excitability and synaptic communication within the oligodendrocyte lineage. J Neurosci 30(10):3600-3611.

Binggeli R, Weinstein RC. 1986. Membrane potentials and sodium channels: Hypotheses for growth regulation and cancer formation based on changes in sodium channels and gap junctions. J Theor Biol 123(4):377-401.

Blankenfeld G v., Verkhratsky AN, Kettenmann H. 1992. Ca2+ Channel Expression in the Oligodendrocyte Lineage. Eur J Neurosci 4(11):1035-1048.

Boda E, Viganò F, Rosa P, Fumagalli M, Labat-Gest V, Tempia F, and others. 2011. The GPR17 receptor in NG2 expressing cells: Focus on in vivocell maturation and participation in acute trauma and chronic damage. Glia 59(12):1958-1973.

Borges K, Wolswijk G, Ohlemeyer C, Kettenmann H. 1995. Adult rat optic nerve oligodendrocyte progenitor cells express a distinct repertoire of voltage- and ligand-gated ion channels. J Neurosci Res 40(5):591-605.

Chan CLH, Wigley CB, Berry M. 1990. Oligodendrocyte-type 2 astrocyte (O-2A) progenitor cells from neonatal and adult rat optic nerve differ in their responsiveness to plateletderived growth factor. Dev Brain Res 55(2):275-282.

Chen TJ, Kula B, Nagy B, Barzan R, Gall A, Ehrlich I, and others. 2018. In Vivo Regulation of Oligodendrocyte Precursor Cell Proliferation and Differentiation by the AMPA-Receptor Subunit GluA2. Cell Rep 25(4):852-861. 
Cheung TH, Rando TA. 2013. Molecular regulation of stem cell quiescence. Nat Rev Mol Cell Biol 14(6):329-340.

Chittajallu R, Aguirre A, Gallo V. 2004. NG2-positive cells in the mouse white and grey matter display distinct physiological properties. J Physiol 561(1):109-122.

Chittajallu R, Aguirre AA, Gallo V. 2005. Downregulation of platelet-derived growth factor- $\alpha$ receptor-mediated tyrosine kinase activity as a cellular mechanism for $\mathrm{K}+$-channel regulation during oligodendrocyte development in situ. J Neurosci 25(38):8601-8610.

Chittajallu R, Chen Y, Wang H, Yuan X, Ghiani CA, Heckman T, and others. 2002. Regulation of Kv1 subunit expression in oligodendrocyte progenitor cells and their role in G1/S phase progression of the cell cycle. Proc Natl Acad Sci U S A 99(4):2350-2355.

Chong SYC, Rosenberg SS, Fancy SPJ, Zhao C, Shen YAA, Hahn AT, and others. 2012. Neurite outgrowth inhibitor Nogo-A establishes spatial segregation and extent of oligodendrocyte myelination. Proc Natl Acad Sci U S A 109(4):1299-1304.

Clarke LE, Young KM, Hamilton NB, Li H, Richardson WD, Attwell D. 2012. Properties and fate of oligodendrocyte progenitor cells in the corpus callosum, motor cortex, and piriform cortex of the mouse. J Neurosci 32(24):8173-8185.

Dawson MR, Polito A, Levine JM, Reynolds R. 2003. NG2-expressing glial progenitor cells: an abundant and widespread population of cycling cells in the adult rat CNS. Mol Cell Neurosci 24(2):476-488.

Van Deursen JM. 2014. The role of senescent cells in ageing. Nature 509(7501):439-446.

Dimou L, Gallo V. 2015. NG2-glia and their functions in the central nervous system. Glia 63(8):1429-1451.

Dimou L, Simons M. 2017. Diversity of oligodendrocytes and their progenitors. Curr Opin Neurobiol 47:73-79.

Etxeberria A, Mangin JM, Aguirre A, Gallo V. 2010. Adult-born SVZ progenitors receive transient synapses during remyelination in corpus callosum. Nat Neurosci 13(3):287-289.

Falcão AM, van Bruggen D, Marques S, Meijer M, Jäkel S, Agirre E, and others. 2018. Diseasespecific oligodendrocyte lineage cells arise in multiple sclerosis. Nat Med 24(12):18371844.

Fannon J, Tarmier W, Fulton D. 2015. Neuronal activity and AMPA-type glutamate receptor activation regulates the morphological development of oligodendrocyte precursor cells. Glia 
63(6):1021-1035.

Fard MK, Van der Meer F, Sánchez P, Cantuti-Castelvetri L, Mandad S, Jäkel S, and others. 2017. BCAS1 expression defines a population of early myelinating oligodendrocytes in multiple sclerosis lesions. Sci Trans1 Med 9(419):eaam7816.

Flechsig P. 1901. Developmental (myelogenetic) localisation of the cerebral cortex in the human subject. Lancet 2(4023):1027-1029.

Foerster S, Hill MFE, Franklin RJM. 2019. Diversity in the oligodendrocyte lineage: Plasticity or heterogeneity? Glia 67(10):1797-1805.

de la Fuente AG, Queiroz RML, Ghosh T, McMurran CE, Cubillos JF, Bergles DE, and others. 2020. Changes in the oligodendrocyte progenitor cell proteome with ageing. Mol Cell Proteomics 19(8):1281-1302.

Franklin RJM, ffrench-Constant C. 2017. Regenerating CNS myelin - from mechanisms to experimental medicines. Nat Rev Neurosci 18(12):753-769.

Franklin RJM, Gilson JM, Blakemore WF. 1997. Local recruitment of remyelinating cells in the repair of demyelination in the central nervous system. J Neurosci. Res 50(2):337-344.

Gallo V, Wright P, McKinnon RD. 1994. Expression and regulation of a glutamate receptor subunit by bFGF in oligodendrocyte progenitors. Glia 10(2):149-153.

Gautier HO, Evans KA, Volbracht K, James R, Sitnikov S, Lundgaard I, and others. 2015. Neuronal activity regulates remyelination via glutamate signalling to oligodendrocyte progenitors. Nat Commun 6:8518.

Geraghty AC, Gibson EM, Ghanem RA, Greene JJ, Ocampo A, Goldstein AK, and others. 2019. Loss of Adaptive Myelination Contributes to Methotrexate Chemotherapy-Related Cognitive Impairment. Neuron 103(2):250-265.

Ghiani CA, Yuan X, Eisen AM, Knutson PL, DePinho RA, McBain CJ, and others. 1999. Voltage-activated $\mathrm{K}+$ channels and membrane depolarization regulate accumulation of the cyclin-dependent kinase inhibitors p27(Kip1) and p21(CIP1) in glial progenitor cells. J Neurosci 19(13):5380-5392.

Gibson EM, Purger D, Mount CW, Goldstein AK, Lin GL, Wood LS, and others. 2014.

Neuronal activity promotes oligodendrogenesis and adaptive myelination in the mammalian brain. Science 344(6183): 1252304.

Gudz TI, Komuro H, Macklin WB. 2006. Glutamate stimulates oligodendrocyte progenitor 
migration mediated via an alphav integrin/myelin proteolipid protein complex. J Neurosci 26(9):2458-2466.

Guo F, Maeda Y, Ko EM, Delgado M, Horiuchi M, Soulika A, and others. 2012. Disruption of NMDA Receptors in Oligodendroglial Lineage Cells Does Not Alter Their Susceptibility to Experimental Autoimmune Encephalomyelitis or Their Normal Development. J Neurosci 32(2):639-645.

Hamano K, Takeya T, Iwasaki N, Nakayama J, Ohto T, Okada Y. 1998. A quantitative study of the progress of myelination in the rat central nervous system, using the immunohistochemical method for proteolipid protein. Brain Res Dev Brain Res 108(12):287-93.

Harlow DE, Saul KE, Komuro H, Macklin WB. 2015. Myelin proteolipid protein complexes with $\alpha \mathrm{v}$ integrin and AMPA receptors in vivo and regulates AMPA-dependent oligodendrocyte progenitor cell migration through the modulation of cell-surface gluR2 expression. J Neurosci 35(34):12018-12032.

Hill RA, Li AM, Grutzendler J. 2018. Lifelong cortical myelin plasticity and age-related degeneration in the live mammalian brain. Nat Neurosci 21(5):683-695.

Hill RA, Patel KD, Goncalves CM, Grutzendler J, Nishiyama A. 2014. Modulation of oligodendrocyte generation during a critical temporal window after NG2 cell division. Nat Neurosci 17(11):1518-1527.

Hill RA, Patel KD, Medved J, Reiss AM, Nishiyama A. 2013. NG2 cells in white matter but not gray matter proliferate in response to PDGF. J Neurosci 33(36):14558-14566.

Hines JH, Ravanelli AM, Schwindt R, Scott EK, Appel B. 2015. Neuronal activity biases axon selection for myelination in vivo. Nat Neurosci 18(5):683-689.

Huang W, Bhaduri A, Velmeshev D, Wang S, Wang L, Rottkamp CA, and others. 2020. Origins and Proliferative States of Human Oligodendrocyte Precursor Cells. Cell 182(3):594-608.

Hughes EG, Kang SH, Fukaya M, Bergles DE. 2013. Oligodendrocyte progenitors balance growth with self-repulsion to achieve homeostasis in the adult brain. Nat Neurosci 16(6):668-676.

Hughes EG, Orthmann-Murphy JL, Langseth AJ, Bergles DE. 2018. Myelin remodeling through experience-dependent oligodendrogenesis in the adult somatosensory cortex. Nat Neurosci 21(5):696-706. 
Jäkel S, Agirre E, Mendanha Falcão A, van Bruggen D, Lee KW, Knuesel I, and others. 2019.

Altered human oligodendrocyte heterogeneity in multiple sclerosis. Nature 566(7745):543547.

Karadottir R, Cavelier P, Bergersen LH, Attwell D. 2005. NMDA receptors are expressed in oligodendrocytes and activated in ischaemia. Nature 438(7071):1162-1166.

Karadottir R, Hamilton NB, Bakiri Y, Attwell D. 2008. Spiking and nonspiking classes of oligodendrocyte precursor glia in CNS white matter. Nat Neurosci 11(4):450-456.

Karram K, Goebbels S, Schwab M, Jennissen K, Seifert G, Steinhauser C, and others. 2008. NG2-expressing cells in the nervous system revealed by the NG2-EYFP-knockin mouse. Genesis 46(12):743-757.

Kessaris N, Fogarty M, Iannarelli P, Grist M, Wegner M, Richardson WD. 2006. Competing waves of oligodendrocytes in the forebrain and postnatal elimination of an embryonic lineage. Nat Neurosci 9(2):173-179.

Kettenmann H, Blankenfeld GV., Trotter J. 1991. Physiological Properties of Oligodendrocytes during Development. Ann N Y Acad Sci 633:64-77.

Kirby L, Jin J, Cardona JG, Smith MD, Martin KA, Wang J, and others. 2019. Oligodendrocyte precursor cells present antigen and are cytotoxic targets in inflammatory demyelination. Nat Commun 10(1):1-20.

Knutson P, Ghiani CA, Zhou JM, Gallo V, McBain CJ. 1997. K+ channel expression and cell proliferation are regulated by intracellular sodium and membrane depolarization in oligodendrocyte progenitor cells. J Neurosci 17(8):2669-2682.

Kougioumtzidou E, Shimizu T, Hamilton NB, Tohyama K, Sprengel R, Monyer H, and others. 2017. Signalling through AMPA receptors on oligodendrocyte precursors promotes myelination by enhancing oligodendrocyte survival. Elife 6:e28080.

Krasnow AM, Ford MC, Valdivia LE, Wilson SW, Attwell D. 2018. Regulation of developing myelin sheath elongation by oligodendrocyte calcium transients in vivo. Nat Neurosci 21(1):24-28.

Kukley M, Nishiyama A, Dietrich D. 2010. The fate of synaptic input to NG2 glial cells: neurons specifically downregulate transmitter release onto differentiating oligodendroglial cells. J Neurosci 30(24):8320-8331.

Larson VA, Zhang Y, Bergles DE. 2016. Electrophysiological properties of NG2+ cells: 
Matching physiological studies with gene expression profiles. Brain Res 1638(Pt B):138160.

Lee S, Leach MK, Redmond SA, Chong SYC, Mellon SH, Tuck SJ, and others. 2012. A culture system to study oligodendrocyte myelination processes using engineered nanofibers. Nat Methods 9(9):917-922.

Lentferink DH, Jongsma JM, Werkman I, Baron W. 2018. Grey matter OPCs are less mature and less sensitive to IFNgamma than white matter OPCs: consequences for remyelination. Sci Rep 8(1):2113.

Lessard F, Igelmann S, Trahan C, Huot G, Saint-Germain E, Mignacca L, and others. 2018. Senescence-associated ribosome biogenesis defects contributes to cell cycle arrest through the Rb pathway. Nat Cell Biol 20(7):789-799.

Levine JM, Reynolds R. 1999. Activation and proliferation of endogenous oligodendrocyte precursor cells during ethidium bromide-induced demyelination. Exp Neurol 160(2):333347.

Lim L, Mi D, Llorca A, Marín O. 2018. Development and Functional Diversification of Cortical Interneurons. Neuron 100(2): 294-313.

Lin G, Mela A, Guilfoyle EM, Goldman JE. 2009. Neonatal and adult O4(+) oligodendrocyte lineage cells display different growth factor responses and different gene expression patterns. J Neurosci Res 87(15):3390-3402.

Lundgaard I, Luzhynskaya A, Stockley JH, Wang Z, Evans KA, Swire M, and others. 2013. Neuregulin and BDNF induce a switch to NMDA receptor-dependent myelination by oligodendrocytes. PLoS Biol 11(12):e1001743.

MacFarlane SN, Sontheimer H. 2000. Changes in ion channel expression accompany cell cycle progression of spinal cord astrocytes. Glia 30(1):39-48.

Maldonado PP, Vélez-Fort M, Levavasseur F, Angulo MC. 2013. Oligodendrocyte precursor cells are accurate sensors of local K+ in mature gray matter. J Neurosci 33(6):2432-2442.

Mallon BS, Elizabeth Shick H, Kidd GJ, Macklin WB. 2002. Proteolipid promoter activity distinguishes two populations of NG2-positive cells throughout neonatal cortical development. J Neurosci 22(3):876-885.

Marinelli C, Bertalot T, Zusso M, Skaper SD, Giusti P. 2016. Systematic Review of Pharmacological Properties of the Oligodendrocyte Lineage. Front Cell Neurosci 10:27. 
Marisca R, Hoche T, Agirre E, Hoodless LJ, Barkey W, Auer F, and others. 2020. Functionally distinct subgroups of oligodendrocyte precursor cells integrate neural activity and execute myelin formation. Nat Neurosci 23(3):363-374.

Marques S, van Bruggen D, Vanichkina DP, Floriddia EM, Munguba H, Varemo L, and others. 2018. Transcriptional Convergence of Oligodendrocyte Lineage Progenitors during Development. Dev Cell 46(4):504-517.

Marques S, Zeisel A, Codeluppi S, Bruggen D van, Falcão AM, Xiao L, and others. 2016. Oligodendrocyte heterogeneity in the mouse juvenile and adult central nervous system. Science 352(6291):1326-1329.

Mason JL, Goldman JE. 2002. A2B5+ and O4+ Cycling Progenitors in the Adult Forebrain White Matter Respond Differentially to PDGF-AA, FGF-2, and IGF-1. Mol Cell Neurosci $20(1): 30-42$.

McKenzie IA, Ohayon D, Li H, de Faria JP, Emery B, Tohyama K, and others. 2014. Motor skill learning requires active central myelination. Science 346(6207):318-322.

Menn B, Garcia-Verdugo JM, Yaschine C, Gonzalez-Perez O, Rowitch D, Alvarez-Buylla A. 2006. Origin of oligodendrocytes in the subventricular zone of the adult brain. J Neurosci 26(30):7907-7918.

Mensch S, Baraban M, Almeida R, Czopka T, Ausborn J, El Manira A, and others. 2015. Synaptic vesicle release regulates myelin sheath number of individual oligodendrocytes in vivo. Nat Neurosci 18(5):628-630.

Micu I, Jiang Q, Coderre E, Ridsdale A, Zhang L, Woulfe J, and others. 2006. NMDA receptors mediate calcium accumulation in myelin during chemical ischaemia. Nature 439(7079):988-992.

Mitew S, Gobius I, Fenlon LR, McDougall SJ, Hawkes D, Xing YL, and others. 2018. Pharmacogenetic stimulation of neuronal activity increases myelination in an axon-specific manner. Nat Commun 9:306.

Morris SA. 2019. The evolving concept of cell identity in the single cell era. Development 146(12):dev169748.

Moshrefi-Ravasdjani B, Dublin P, Seifert G, Jennissen K, Steinhäuser C, Kafitz Karl W, and others. 2017. Changes in the proliferative capacity of NG2 cell subpopulations during postnatal development of the mouse hippocampus. Brain Struct Funct 222(2):831-847. 
Moyon S, Dubessy AL, Aigrot MS, Trotter M, Huang JK, Dauphinot L, and others. 2015. Demyelination causes adult CNS progenitors to revert to an immature state and express immune cues that support their migration. J Neurosci 35(1):4-20.

Nave KA. 2010. Myelination and the trophic support of long axons. Nat Rev Neurosci 11(4):275-283.

Nawaz S, Sánchez P, Schmitt S, Snaidero N, Mitkovski M, Velte C, and others. 2015. Actin Filament Turnover Drives Leading Edge Growth during Myelin Sheath Formation in the Central Nervous System. Dev Cell 34(2):139-151.

Neumann B, Baror R, Zhao C, Segel M, Dietmann S, Rawji KS, and others. 2019. Metformin Restores CNS Remyelination Capacity by Rejuvenating Aged Stem Cells. Cell Stem Cell 25(4):473-485.

Neumann B, Foerster S, Zhao C, Bodini B, Reich DS, Bergles DE, and others. 2020. Problems and Pitfalls of Identifying Remyelination in Multiple Sclerosis. Cell Stem Cell 26(5):617619.

Nishiyama A, Lin XH, Giese N, Heldin CH, Stallcup WB. 1996. Co-localization of NG2 proteoglycan and PDGF $\alpha$-receptor on O2A progenitor cells in the developing rat brain. $\mathrm{J}$ Neurosci Res 43(3):299-314.

Osanai Y, Shimizu T, Mori T, Yoshimura Y, Hatanaka N, Nambu A, and others. 2017. Rabies virus-mediated oligodendrocyte labeling reveals a single oligodendrocyte myelinates axons from distinct brain regions. Glia 65(1):93-105.

Pajevic S, Basser PJ, Fields RD. 2014. Role of myelin plasticity in oscillations and synchrony of neuronal activity. Neuroscience 276:135-147.

Pan S, Mayoral SR, Choi HS, Chan JR, Kheirbek MA. 2020. Preservation of a remote fear memory requires new myelin formation. Nat Neurosci 23(4):487-499.

Parras CM, Hunt C, Sugimori M, Nakafuku M, Rowitch D, Guillemot F. 2007. The proneural gene Mash1 specifies an early population of telencephalic oligodendrocytes. J Neurosci 27(16):4233-4242.

Pepper RE, Pitman KA, Cullen CL, Young KM. 2018. How do cells of the oligodendrocyte lineage affect neuronal circuits to influence motor function, memory and mood? Front Cell Neurosci 12:399.

Pereira SPF, Araujo EG. 1997. Veratridine increases the survival of retinal ganglion cells in 
vitro. Brazilian J Med Biol Res 30(12):1467-1470.

Perlman K, Couturier CP, Yaqubi M, Tanti A, Cui QL, Pernin F, and others. 2020.

Developmental trajectory of oligodendrocyte progenitor cells in the human brain revealed by single cell RNA sequencing. Glia 68(6):1291-1303.

Pivonkova H, Benesova J, Butenko O, Chvatal A, Anderova M. 2010. Impact of global cerebral ischemia on $\mathrm{K}+$ channel expression and membrane properties of glial cells in the rat hippocampus. Neurochem Int 57(7):783-794.

Psachoulia K, Jamen F, Young KM, Richardson WD. 2009. Cell cycle dynamics of NG2 cells in the postnatal and ageing brain. Neuron Glia Biol 5(3-4):57-67.

del Río-Hortega P. 1928. Tercera aportación al conocimiento morfológico e interpretación funcional de la oligodendroglía. Mem Soc Esp Hist Nat 14:5-122.

Rivers LE, Young KM, Rizzi M, Jamen F, Psachoulia K, Wade A, and others. 2008. PDGFRA/NG2 glia generate myelinating oligodendrocytes and piriform projection neurons in adult mice. Nat Neurosci 11(12):1392-1401.

Rogers SW, Gregori NZ, Carlson N, Gahring LC, Noble M. 2001. Neuronal nicotinic acetylcholine receptor expression by $\mathrm{O} 2 \mathrm{~A} /$ oligodendrocyte progenitor cells. Glia 33(4):306-313.

Ruckh JM, Zhao JW, Shadrach JL, van Wijngaarden P, Rao TN, Wagers AJ, and others. 2012. Rejuvenation of regeneration in the aging central nervous system. Cell Stem Cell 10(1):96103.

Saab AS, Tzvetavona ID, Trevisiol A, Baltan S, Dibaj P, Kusch K, and others. 2016.

Oligodendroglial NMDA Receptors Regulate Glucose Import and Axonal Energy Metabolism. Neuron 91(1):119-132.

Salvesen L, Winge K, Brudek T, Agander TK, Løkkegaard A, Pakkenberg B. 2017. Neocortical Neuronal Loss in Patients with Multiple System Atrophy: A Stereological Study. Cereb Cortex 27(1):400-410.

Segel M, Neumann B, Hill MFE, Weber IP, Viscomi C, Zhao C, and others. 2019. Niche stiffness underlies the ageing of central nervous system progenitor cells. Nature 573(7772):130-134.

Shi J, Marinovich A, Barres BA. 1998. Purification and characterization of adult oligodendrocyte precursor cells from the rat optic nerve. J Neurosci 18(12)4627-4636. 
Schirmer L, Velmeshev D, Holmqvist S, Kaufmann M, Werneburg S, Jung D, and others. 2019. Neuronal vulnerability and multilineage diversity in multiple sclerosis. Nature 573(7772):75-82.

Sontheimer H, Trotter J, Schachner M, Kettenmann H. 1989. Channel expression correlates with differentiation stage during the development of oligodendrocytes from their precursor cells in culture. Neuron 2(2):1135-1145.

Spitzer SO, Sitnikov S, Kamen Y, Evans KA, Kronenberg-Versteeg D, Dietmann S, and others. 2019. Oligodendrocyte Progenitor Cells Become Regionally Diverse and Heterogeneous with Age. Neuron 101(3):459-471.

Steadman PE, Xia F, Ahmed M, Mocle AJ, Penning ARA, Geraghty AC, and others. 2020. Disruption of Oligodendrogenesis Impairs Memory Consolidation in Adult Mice. Neuron 105(1):150-164.

Swire M, Kotelevtsev Y, Webb, DJ, Lyons DA, ffrench-Constant C. 2019. Endothelin signalling mediates experience-dependent myelination in the CNS. Elife 8:e49493.

Terzi MY, Izmirli M, Gogebakan B. 2016. The cell fate: senescence or quiescence. Mol. Biol. Rep. 43(11):1213-1220.

Tiwari-Woodruff S, Beltran-Parrazal L, Charles A, Keck T, Vu T, Bronstein J. 2006. ${ }^{+}$channel $\mathrm{K}$ v 3.1 associates with OSP/claudin-11 and regulates oligodendrocyte development. Am J Physiol Physiol 291(4):C687-C698.

Tripathi RB, Clarke LE, Burzomato V, Kessaris N, Anderson PN, Attwell D, and others. 2011. Dorsally and ventrally derived oligodendrocytes have similar electrical properties but myelinate preferred tracts. J Neurosci 31(18):6809-6819.

Tripathi RB, Rivers LE, Young KM, Jamen F, Richardson WD. 2010. NG2 Glia Generate New Oligodendrocytes But Few Astrocytes in a Murine Experimental Autoimmune Encephalomyelitis Model of Demyelinating Disease. J Neurosci 30(48):16383-16390

Urrego D, Tomczak AP, Zahed F, Stühmer W, Pardo LA. 2014. Potassium channels in cell cycle and cell proliferation. Philos Trans R Soc B Biol Sci 369(1638):20130094.

Vautier F, Belachew S, Chittajallu R, Gallo V. 2004. Shaker-type potassium channel subunits differentially control oligodendrocyte progenitor proliferation. Glia 48(4):337-345.

Vélez-Fort M, Audinat E, Angulo MC. 2009. Functional $\alpha 7$-containing nicotinic receptors of NG2-expressing cells in the hippocampus. Glia 57(10):1104-1114. 
Vélez-Fort M, Maldonado PP, Butt AM, Audinat E, Angulo MC. 2010. Postnatal switch from synaptic to extrasynaptic transmission between interneurons and NG2 cells. J Neurosci 30(20):6921-6929.

Viganò F, Möbius W, Götz M, Dimou L. 2013. Transplantation reveals regional differences in oligodendrocyte differentiation in the adult brain. Nat Neurosci 16(10):1370-1372.

Wang C, Pralong WF, Schulz MF, Rougon G, Aubry JM, Pagliusi S, and others. 1996. Functional N-methyl-D-aspartate receptors in O-2A glial precursor cells: a critical role in regulating polysialic acid-neural cell adhesion molecule expression and cell migration. $\mathrm{J}$ Cell Biol 135(6 Pt 1):1565-1581.

Wang F, Ren SY, Chen JF, Liu K, Li RX, Li ZF, and others. 2020. Myelin degeneration and diminished myelin renewal contribute to age-related deficits in memory. Nat Neurosci 23(4):481-486.

Wang J, Saraswat D, Sinha AK, Polanco J, Dietz K, O’Bara MA, and others. 2018. Paired Related Homeobox Protein 1 Regulates Quiescence in Human Oligodendrocyte Progenitors. Cell Rep 25(12):3435-3450.

Wolswijk G. 1998. Chronic stage multiple sclerosis lesions contain a relatively quiescent population of oligodendrocyte precursor cells. J Neurosci 18(2):601-609.

Wolswijk G, Noble M. 1989. Identification of an adult-specific glial progenitor cell. Development 105(2):387-400.

Xie M, Lynch DT, Schools GP, Feustel PJ, Kimelberg HK, Zhou M. 2007. Sodium channel currents in rat hippocampal NG2 glia: Characterization and contribution to resting membrane potential. Neuroscience 150(4):853-862.

Ximerakis M, Lipnick SL, Innes BT, Simmons SK, Adiconis X, Dionne D, and others. 2019. Single-cell transcriptomic profiling of the aging mouse brain. Nat Neurosci 22(10):16961708

Yeung MSY, Djelloul M, Steiner E, Bernard S, Salehpour M, Possnert G, and others. 2019. Dynamics of oligodendrocyte generation in multiple sclerosis. Nature 566(7745):538-542. Young KM, Fogarty M, Kessaris N, Richardson WD. 2007. Subventricular zone stem cells are heterogeneous with respect to their embryonic origins and neurogenic fates in the adult olfactory bulb. J Neurosci 27(31):8286-8296.

Young KM, Psachoulia K, Tripathi RB, Dunn SJ, Cossell L, Attwell D, and others. 2013. 
Oligodendrocyte dynamics in the healthy adult CNS: evidence for myelin remodeling. Neuron 77(5):873-885.

Yuan X, Eisen AM, McBain CJ, Gallo V. 1998. A role for glutamate and its receptors in the regulation of oligodendrocyte development in cerebellar tissue slices. Development 125(15):2901-2914.

Zeisel A, Moz-Manchado AB, Codeluppi S, Lönnerberg P, Manno G La, Juréus A, and others. 2015. Cell types in the mouse cortex and hippocampus revealed by single-cell RNA-seq. Science 347(6226):1138-1142.

Zhang Y, Chen K, Sloan SA, Bennett ML, Scholze AR, O'Keeffe S, and others. 2014. An RNAsequencing transcriptome and splicing database of glia, neurons, and vascular cells of the cerebral cortex. J Neurosci 34(36):11929-11947.

Ziskin JL, Nishiyama A, Rubio M, Fukaya M, Bergles DE. 2007. Vesicular release of glutamate from unmyelinated axons in white matter. Nat Neurosci 10(3):321-330.

Zonouzi M, Renzi M, Farrant M, Cull-Candy SG. 2011. Bidirectional plasticity of calciumpermeable AMPA receptors in oligodendrocyte lineage cells. Nat Neurosci 14(11):14301438. 
Figure Legends

Figure 1. Oligodendrocyte lineage cells exhibit distinct antigenic and electrophysiological properties

Summary of the antigenic and electrophysiological properties of oligodendrocyte (OL) lineage cells. The top panel displays antigens that are typically used to distinguish OL lineage cells. SOX10 and OLIG2 label all oligodendrocyte lineage cells, but oligodendrocyte precursor cells (OPCs) are defined by the additional expression of PDGFR $\alpha$ and NG2, while immature OLs can be labelled with O4, and myelinating OLs express MOG. However, some antigen markers such as O4, GalC, CC1, MBP and PLP can be detected as cells transition between stages in the lineage. OL lineage cells have typical electrophysiological profiles (bottom panel) in response to the application of voltage steps (boxed, $20 \mathrm{mV}$ pulses from $-134 \mathrm{mV}$ to $26 \mathrm{mV}$ applied from a holding potential of $-74 \mathrm{mV}$ ). OPCs typically exhibit fast outward voltage-gated potassium currents, delayed outward voltage-gated potassium currents and fast inward tetrodotoxin-sensitive voltagegated sodium currents ( $\mathrm{Nav}$ ) (left). However, some OPCs lack these voltage-gated ion channels (right). Both types of OPCs lack the tail current observed in immature and mature OLs. The two insets show leak-subtracted traces of fast inward voltage-gated sodium currents and fast outward voltage-gated potassium currents (left), or a lack of voltage-gated currents (right). Immature OLs lack voltage-gated currents, but display passive, ohmic, current responses and exhibit tail currents. Myelinating OLs display the same properties as immature OLs, but with lower membrane resistances.

\section{Figure 2. Oligodendrocyte precursor cell membrane properties alter with age}

Oligodendrocyte precursor cells (OPCs) were voltage-clamped in the cortex and corpus callosum of NG2-EYFP mice at different developmental timepoints. (A) Representative leak-subtracted traces of fast inward tetrodotoxin-sensitive voltage-gated sodium currents recorded at embryonic day 13 (E13), during the first two postnatal weeks (P6-16), and at nine months. Voltage-gated sodium currents are not detected at E13, peak in density during the first two postnatal weeks, and decrease with age. (B) Representative current responses to the application of $30 \mu \mathrm{M}$ kainate. Kainate does not evoke a response at E13, but evokes responses in postnatal OPCs, and the density of kainate receptors increases with age. (C) Representative NMDA $(60 \mu \mathrm{M})$-evoked currents. 
NMDA currents are not detected at E13 or nine months, but are detected in the first two postnatal weeks. (D) Proportion of NG2-EYFP cells with outward voltage-gated potassium channels $\left(\mathrm{K}_{\mathrm{V}}\right)$, AMPA/kainate receptors (KAR), voltage-gated sodium channels $\left(\mathrm{Na} \mathrm{V}_{\mathrm{V}}\right)$ and NMDA receptors (NMDAR) between E13 and nine months. At E13, OPCs lack voltage-gated channels and glutamate receptors. $\mathrm{K}_{V}, \mathrm{AMPA} / \mathrm{KAR}$ and $\mathrm{Na}_{\mathrm{V}}$ are first detected at $\mathrm{E} 18$, in varying proportions. By birth (P0), all OPCs exhibit $\mathrm{K}_{\mathrm{V}}$ and AMPA/KAR, and the majority of OPCs have Nav. NMDAR appear by P0, peak in the first postnatal month, and disappear by nine months. Panels A-D are adapted from Spitzer and others, Neuron 2019 (with permission according to a Creative Commons Attribution License (CC BY)).

\section{Figure 3. Oligodendrocyte precursor cell states}

Drawing from fields across biology, and correlating transcriptomic, proteomic, single-cell electrophysiology and functional data we propose that oligodendrocyte precursor cells (OPCs) exist in six distinct functional states. From left to right, first, the naïve OPC, lacking ion channels and glutamate receptors, but likely marked by EGFR expression along with cell cycle, neural progenitors and transcription factor activity genes. Second, the migratory OPC, marked by voltagegated potassium channels $\left(\mathrm{K}_{\mathrm{V}}\right)$, AMPA/kainate receptors (AMPA/KAR), and the expression of migratory and cytoskeletal genes. Third, a highly proliferative OPC, marked by $\mathrm{K}_{\mathrm{v}}$, AMPA/KAR, a high density of voltage-gated sodium channels $(\mathrm{Nav})$, and high expression of cell cycle genes. Fourth, a primed OPC, characterised by $\mathrm{K}_{\mathrm{V}}, \mathrm{Nav}_{\mathrm{v}}$, AMPA/KAR, NMDA receptors (NMDAR), and high levels of differentiation, metabolic, signal transduction and synaptic signalling genes. Fifth, a quiescent OPC, marked by a $\mathrm{K}_{\mathrm{V}}, \mathrm{Nav}$, a high density of AMPA/KAR, a decrease in cell cycle genes, and an increased quiescent signature. Sixth, a potential senescent state, marked by an increase in $C d k n 2 a$ transcript levels and a decrease in ribosome biogenesis. The electrophysiological profile of this cell state is not currently known. Cell capacitance varies between states; as drawn here, larger cells represent states with a larger cell capacitance, while smaller cells have a lower capacitance. The six OPC states of OPCs can be further divided into two groups: states with ongoing proliferation, or states in cell cycle arrest/exit, as indicated above the depicted states. These states are generally observed as a temporal progression (black arrows), but may be reversible (grey arrows), although the extent of and how OPCs transition between states is still elusive. 


\section{Figure 4. Oligodendrocyte precursor cell state distribution with age and brain region}

Approximate proportions of each oligodendrocyte precursor cell (OPC) state found in different brain regions at different timepoints, as determined by electrophysiology (Spitzer and others 2019). The proportions represented here are based on the proportion of OPCs with voltage-gated ion channels and glutamate receptors as shown in figures 1, 4, and 6 from Spitzer and others (2019). At embryonic day 13 (E13), all OPCs are naïve. Postnatally, the proportion of each state varies with age and brain region, following function. For instance, the proportion of primed OPCs is highest in the cortex and corpus callosum at P30, at the peak of myelination, but remains low in OPCs recorded in the cerebellar molecular layer, where there is no myelination.

Figure 5. Single-cell RNA sequencing of oligodendrocytes indicates that they are diverse, and altered in experimental autoimmune encephalitis and multiple sclerosis

t-stochastic neighbour embedding (t-SNE) analysis of single-cell sequencing of oligodendrocyte lineage cells suggests that mature oligodendrocytes exhibit diversity. (A) t-SNE projection of oligodendrocyte lineage cells in the juvenile and adult posterior forebrain or spinal cord reveals a developmental trajectory from oligodendrocyte precursor cells (OPCs) to several mature oligodendrocyte (MOL) clusters. VLMC, vascular and leptomeningeal cells; COP, committed oligodendrocyte precursor; NFOL, newly formed oligodendrocyte; MFOL, myelin forming oligodendrocyte. From Marques and others. 2016. Oligodendrocyte heterogeneity in the mouse juvenile and adult central nervous system. Science 352(6291):1326-1329. https://science.sciencemag.org/content/352/6291/1326 Reprinted with permission from AAAS.

(B) t-SNE plot of oligodendrocyte lineage cells sequenced from adult spinal cord in control and experimental autoimmune encephalitis (EAE) mice. Cluster identities were based on Marques and others 2016. MOL populations differ between control and EAE samples. Reprinted by permission from Springer Nature: Nature Research, Nature Medicine. Disease-specific oligodendrocyte lineage cells arise in multiple sclerosis. Falcão and others. Copyright (C) 2018, Springer Nature. 2018. (C) t-SNE projection of single-nuclei sequencing of white matter oligodendrocyte lineage cells from frozen control and multiple sclerosis patient brains. Several mature oligodendrocyte clusters were identified, and the proportion of cells in individual clusters is altered in multiple sclerosis. Reprinted by permission from Springer Nature: Nature Research, Nature. Altered human 
oligodendrocyte heterogeneity in multiple sclerosis. Jäkel and others. Copyright (C 2019, Springer Nature. 2019. (D) Summary table of potential oligodendrocyte states identified from single-cell sequencing of murine cells or single-nuclei sequencing of human cells. Both mouse and human oligodendrocytes appear to follow a similar progression through functional states, and the proportion of cells in individual clusters is altered in both EAE and multiple sclerosis. Further, murine and human cell clusters may be correlated: grey dashed lines indicate potential correlations between murine and human cell clusters based on transcriptome (Jäkel and others 2019). However, differences in species, region, and methodology can make these correlations difficult, and thus, these remain tentative.

\section{Figure 6. Possible oligodendrocyte functions - does oligodendrocyte diversity underlie functional states?}

Single-cell sequencing studies have identified up to six different myelinating oligodendrocyte clusters. Analysis of differential gene expression between these clusters suggests that they may represent different stages of myelination, or different functional states. For instance, these clusters may underlie oligodendrocytes engaged in sheath elongation or retraction, altering sheath thickness in response to neuronal activity-driven vesicle (white circles) release at the axo-myelinic synapse, ensheathing an axon, providing metabolic support to an axon (metabolites in green), or locating an active axon to myelinate, but this remains to be further determined.

\section{Figure 7. Two modes of myelination: activity-dependent and activity-independent myelination}

(A) Schematic diagram of the two modes of myelination and how the switch between them is activated. The presence of neuregulin (NRG)/BDNF and active axons, releasing glutamate, triggers the switch from activity-independent myelination to activity-dependent myelination, where OPCs display increased sensitivity to neuronal activity (increased NMDA currents), and myelination occurs faster compared to the default mode. In the absence of either NRG or BDNF myelination proceeds via the default program irrespective of activity, however the presence of activity and glutamate release is required in addition to the growth factors in order to trigger the switch to activity-dependent myelination. (B) Shows some of the data supporting the switch between myelination modes in neuron-OPC cocultures. In the absence of NRG, blocking neuronal 
activity with tetrodotoxin (TTX), NMDA receptors with MK-801 (MK) or both neuronal activity and NMDA receptors (TTX MK) does not affect myelination as the switch is not triggered. Addition of NRG to cocultures without blocking baseline activity triggers the switch to activitydependent myelination. Blockade of NMDA receptors with the open channel antagonist MK-801 in the presence of NRG reduces myelination to $25 \%$ of control levels as the switch to activity dependence is triggered, but the activity can no longer be detected by the NMDA receptors. Blocking activity with TTX, or blocking both activity and NMDA receptors, in the presence of NRG prevents the switch from occurring, demonstrated by similar myelination levels as in the absence of NRG. $* * * p<0.001$. (C) Addition of NRG to neuron-OPC cocultures both increases and accelerates myelination. (D) In the presence of NRG, NMDA $(60 \mu \mathrm{M})$-evoked currents increase in OPCs, while kainate $(30 \mu \mathrm{M})$-evoked currents do not change, suggesting an increase in the proportion of primed cells. ${ }^{*} \mathrm{p}<0.05$. (E) Representative traces for NMDA- and kainate-evoked currents recorded in voltage-clamped OPCs in the presence or absence of NRG. Panels B, C and D are adapted from Lundgaard and others, PLOS Biology 2013 (with permission according to a Creative Commons Attribution License (CC BY)). 
NG2 / PDGFRa / Nkx2.2

\section{O4}

GalC / CC1

MBP / PLP

MOG

OPC

$\mathrm{OPC}\left(\mathrm{No} \mathrm{Na}_{v}\right)$

Immature OL

Myelinating OL

خ्रै०
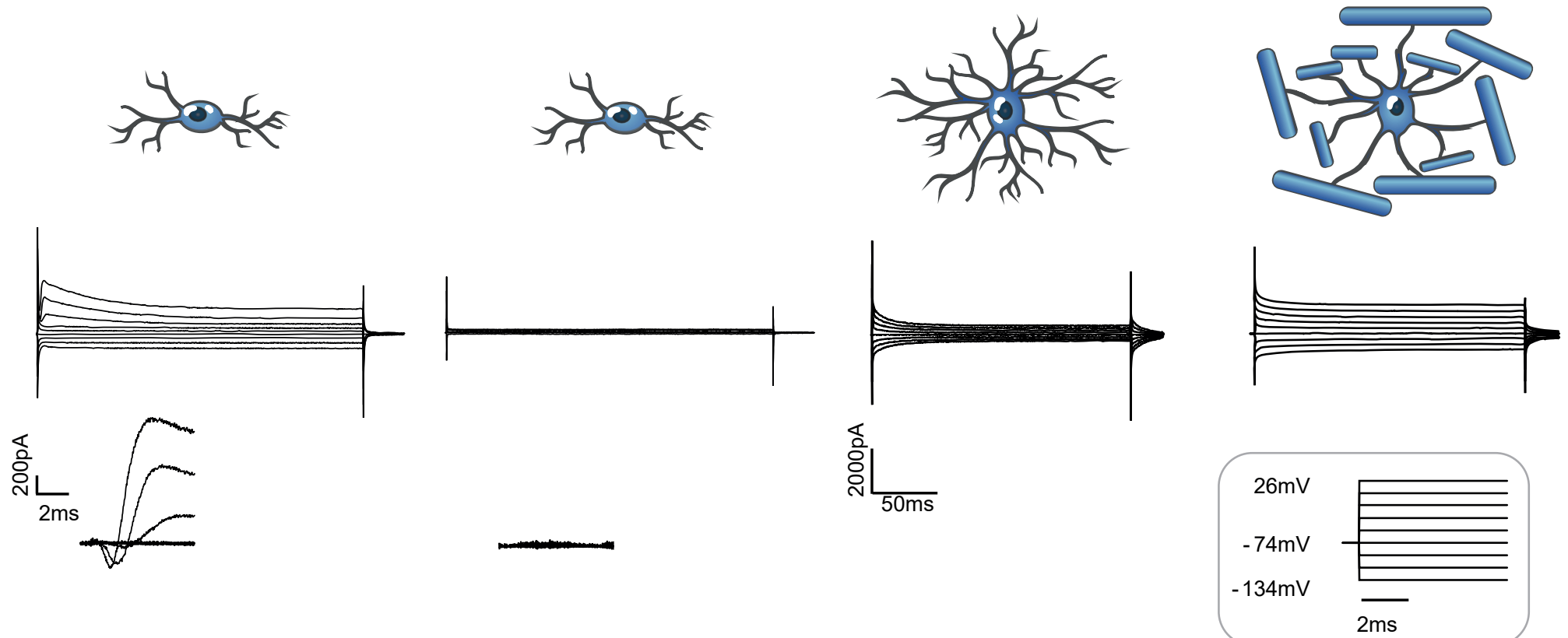

Figure 1 

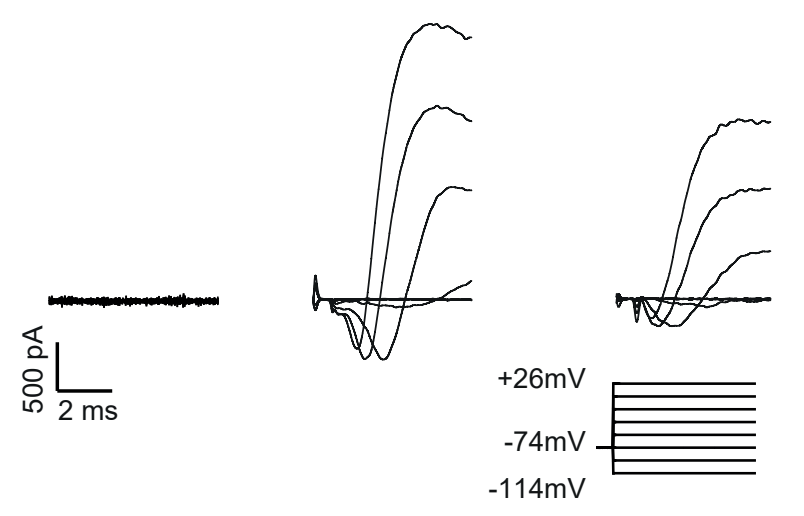

B
E13
P6-16
$9 \mathrm{~m}$

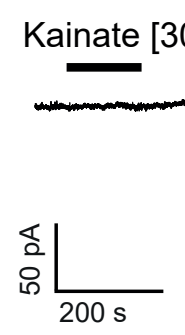

C

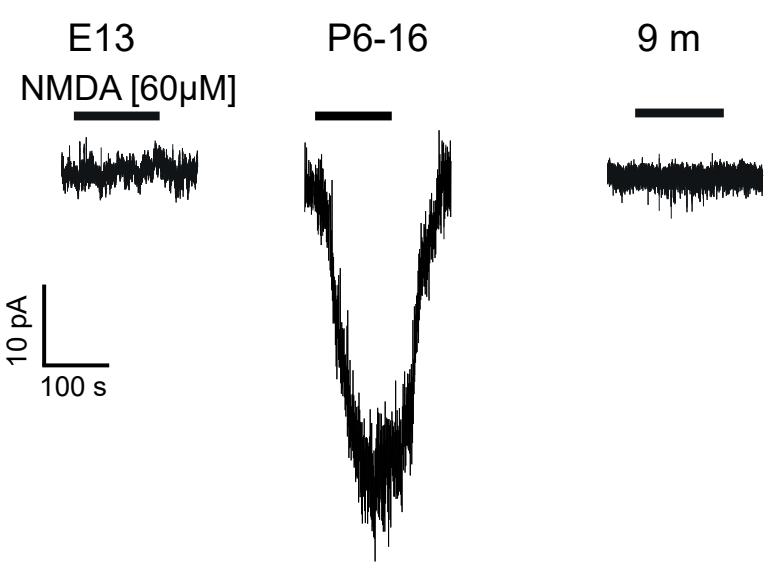

D
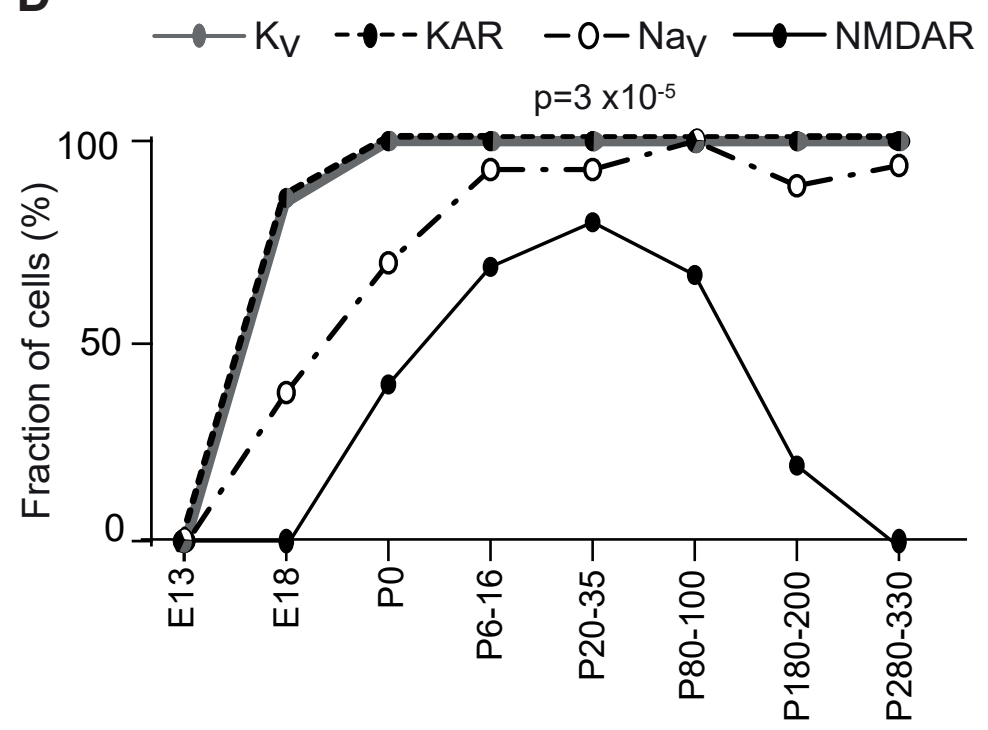

Figure 2 


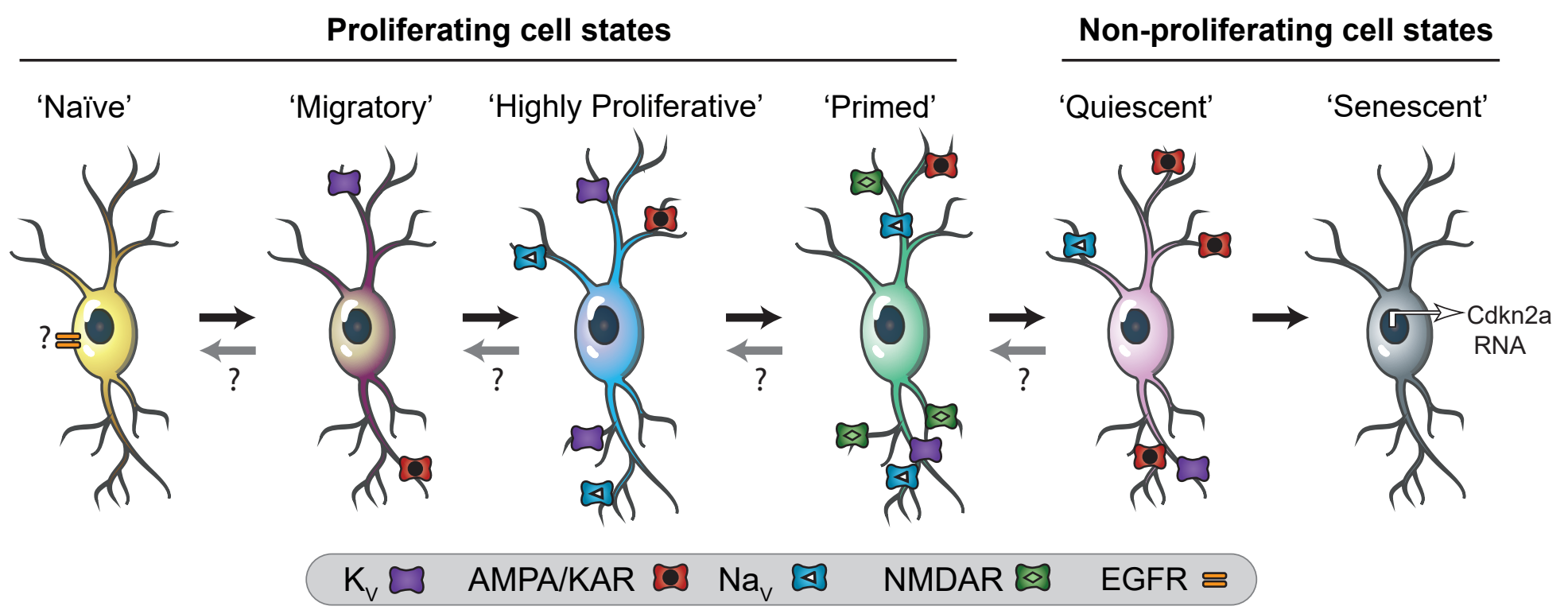

Figure 3 


\section{$\begin{array}{lllll}\text { E13 } & \text { P12 } & \text { P30 } & \text { P180 } & \text { P330 }\end{array}$}

\section{Cortex}
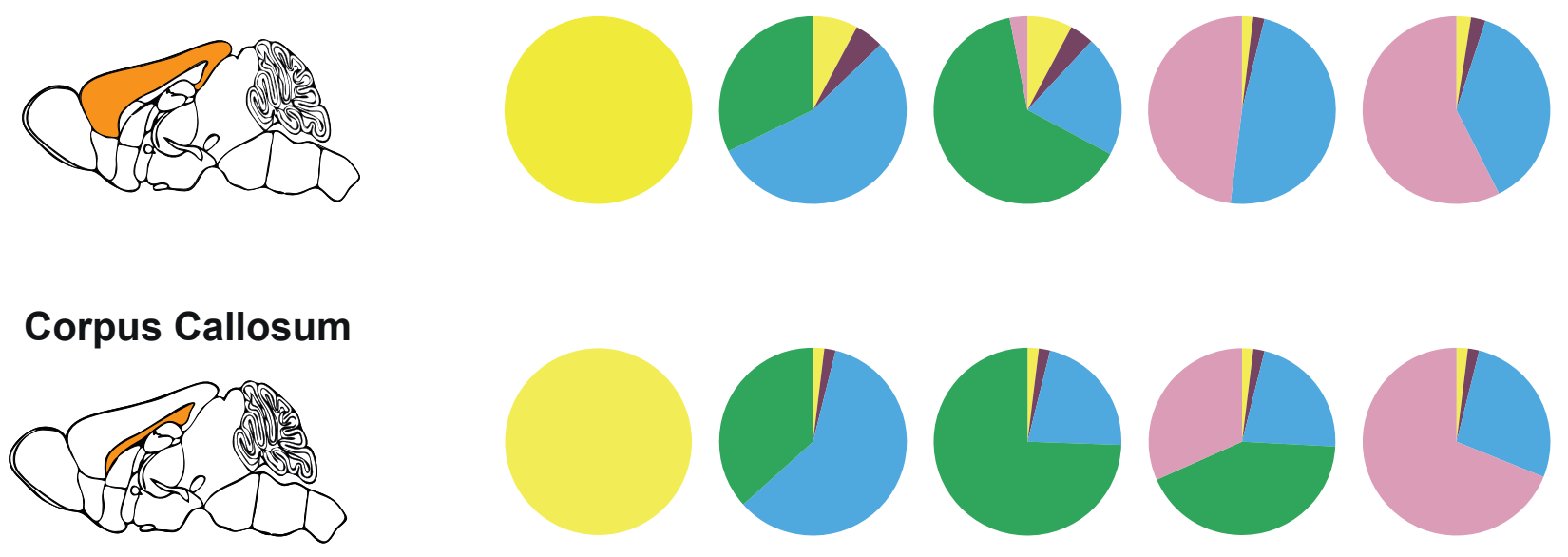

\section{Cerebellum}
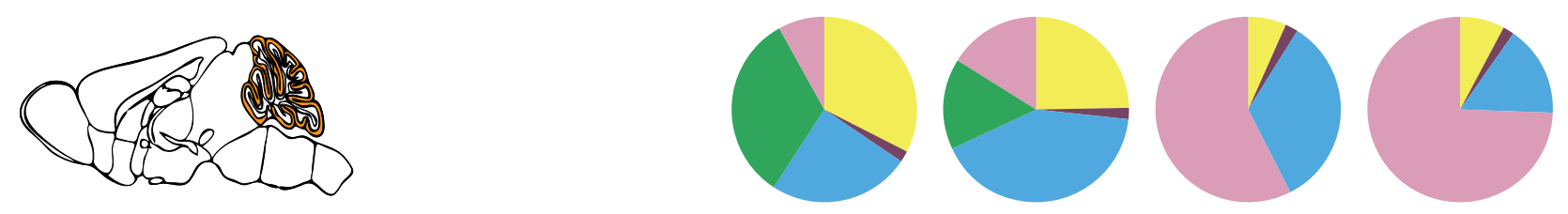

Subventricular Zone
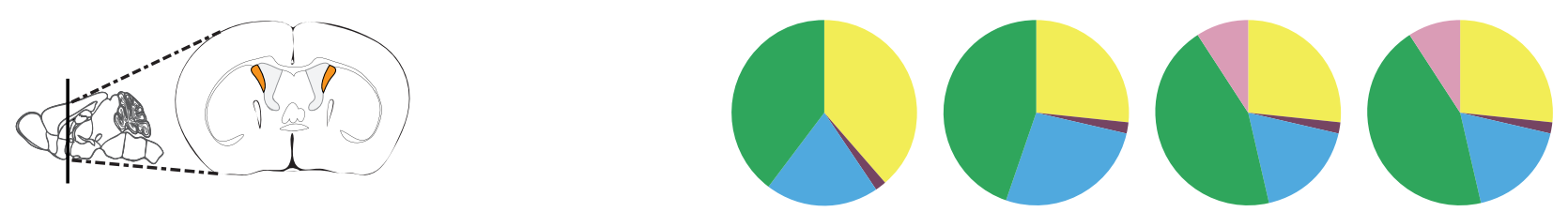
A

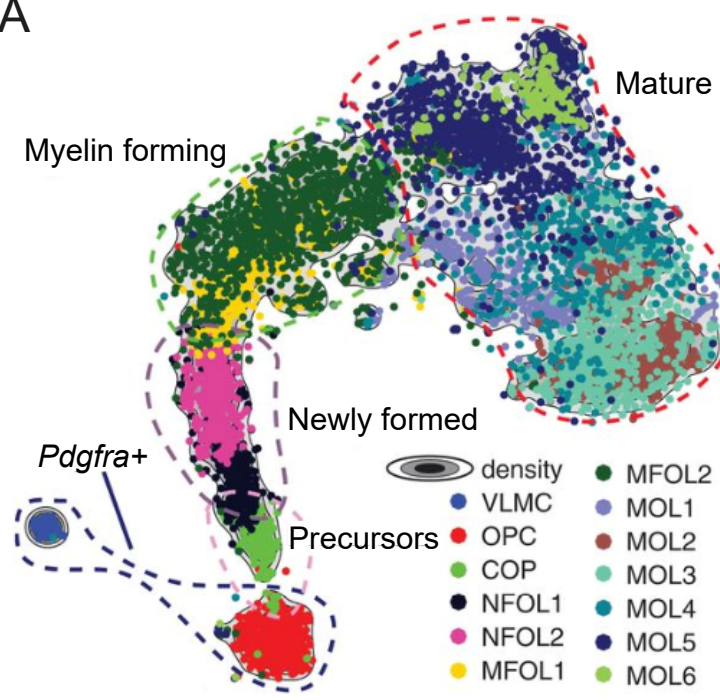

B
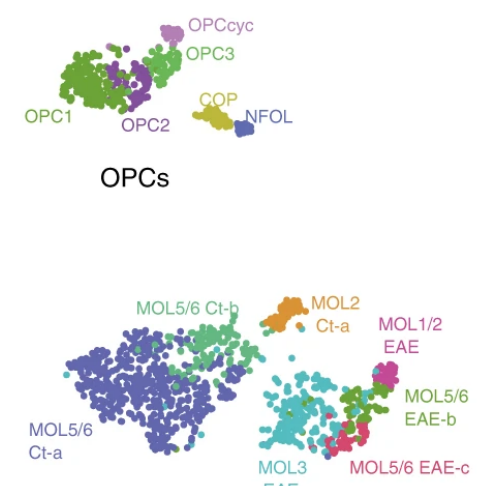

OLs

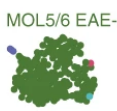

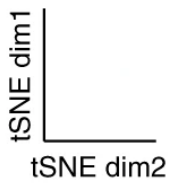

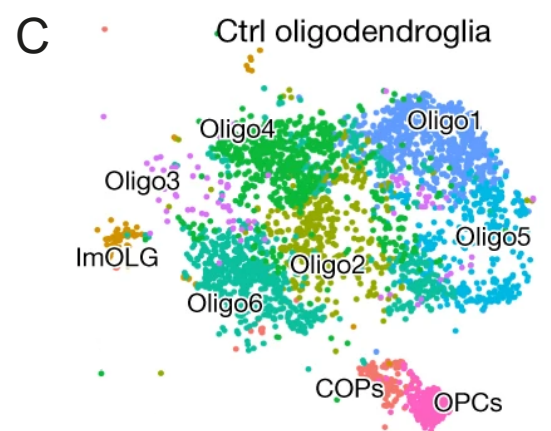

MS oligodendroglia

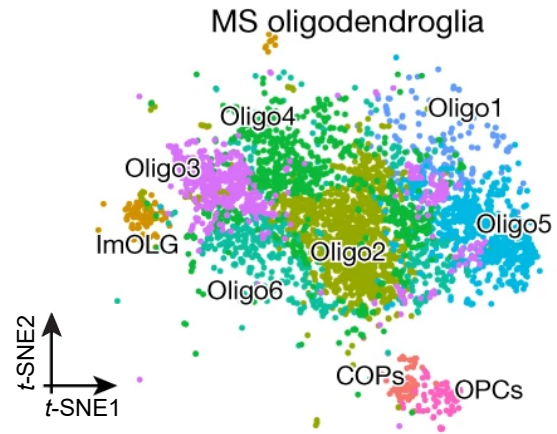

D

Zeisel and others 2015 Marques and others 2016

Mouse

OL1

OL2

OL3

OL4

OL5

Myelinating OLs

High expression of myelination genes

Terminally differentiated OLs

Low expression of myelination genes

High expression of signalling, adhesion

and viability genes
Falcao and others 2018

$$
\text { Mouse }
$$

NFOL1

NFOL2

MFOL1

MFOL2

MOL1

MOL2

MOL3

MOL4

MOL5

MOL6
Jäkel and others 2019

Human

Oligo6 Intermediate between OPCs and OLs

Oligo3 Myelinating OLs

High expression of myelination genes and membrane assembly

Terminally differentiated OLs

enriched in EAE or MS

depleted in MS 


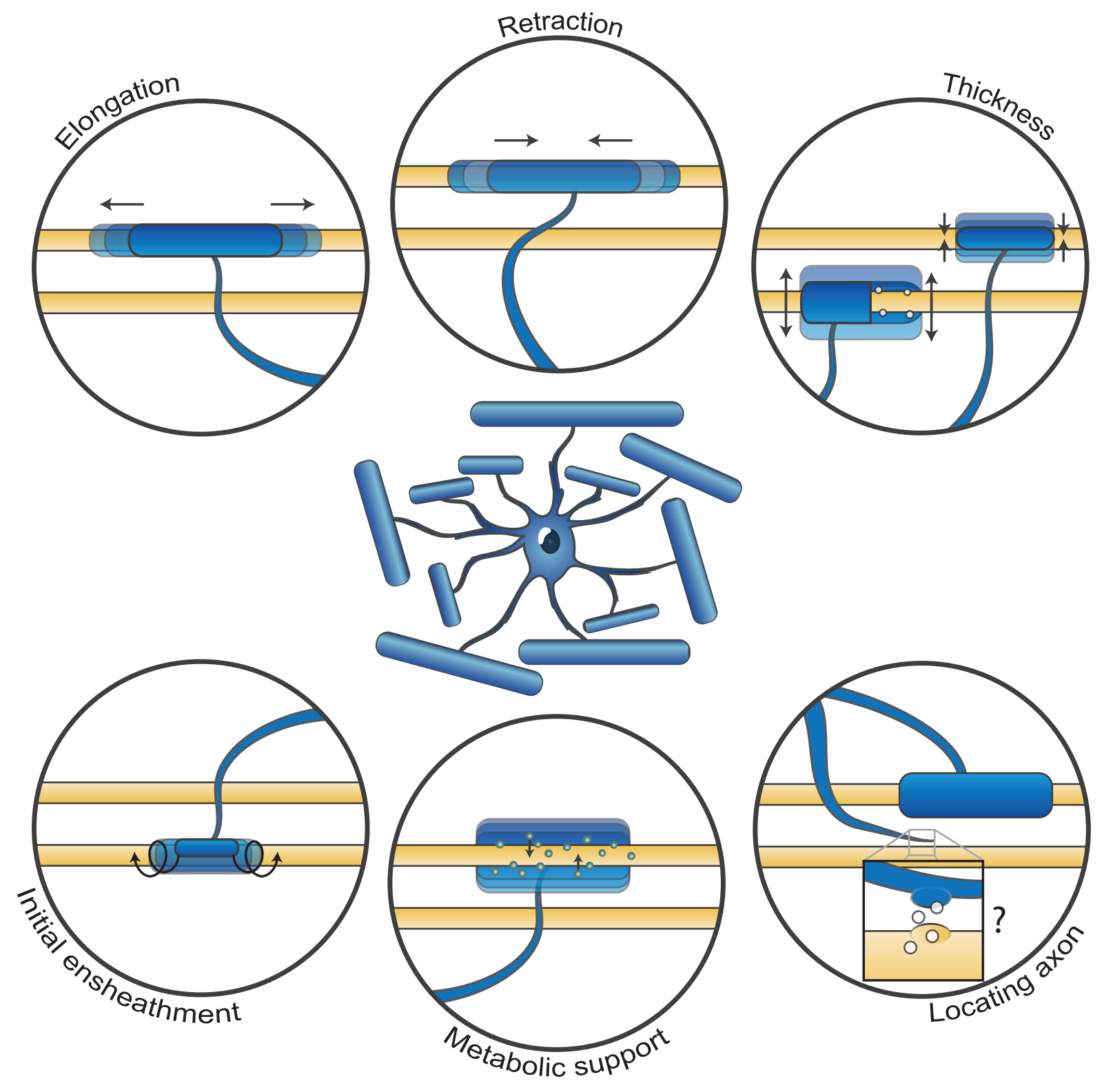

Figure 6 


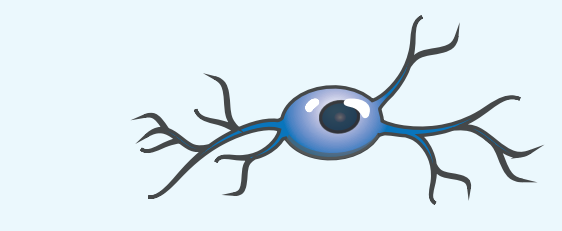

NRG/BDNF +

Activity \& Glutamate
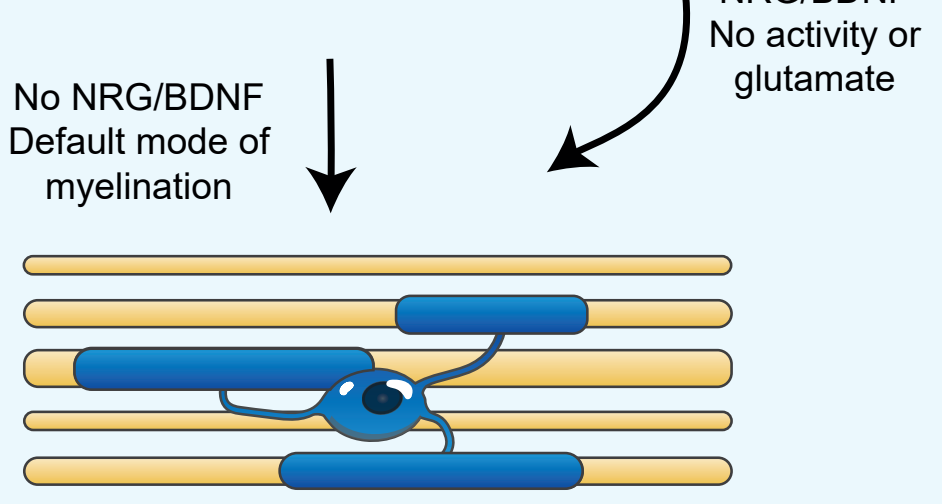

Activity independent myelination

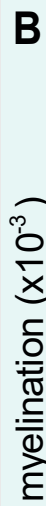

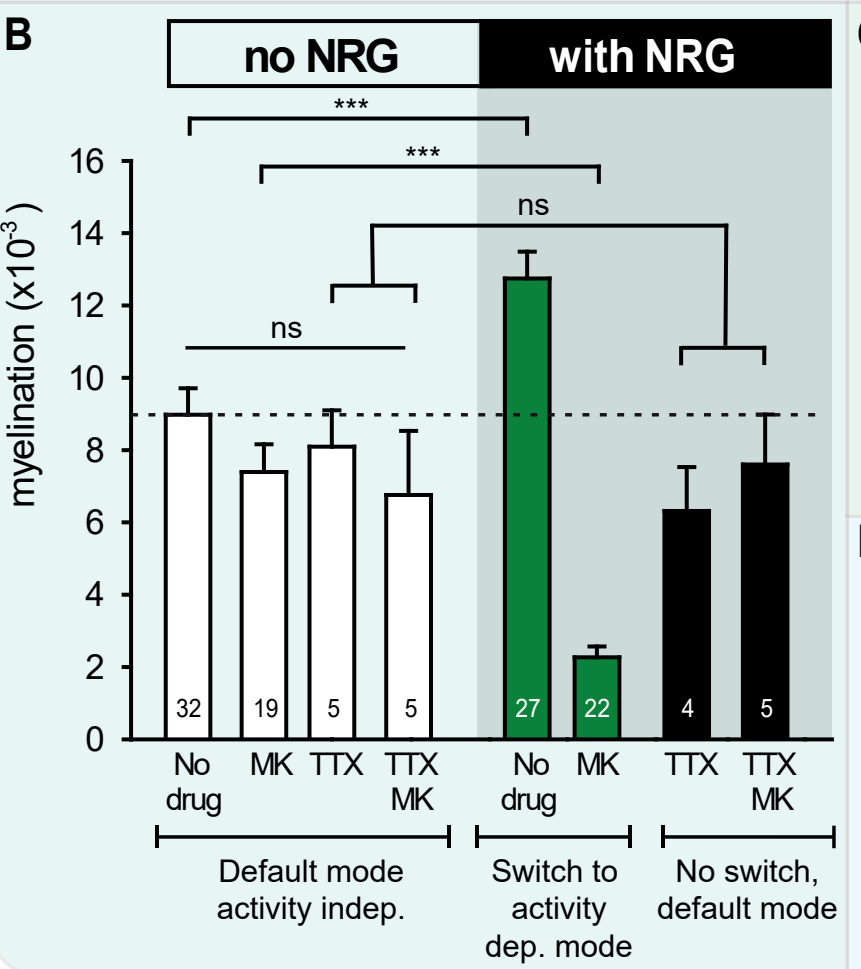

D

\section{Switch occurs}

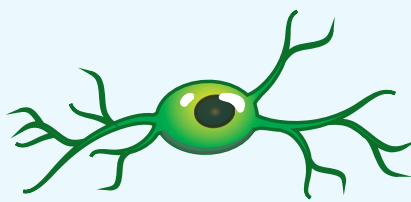

Increased sensitivity
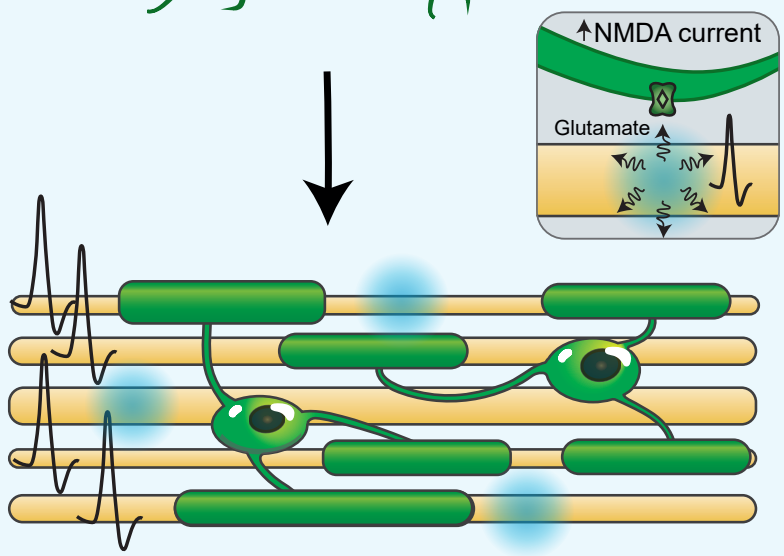

Activity dependent myelination
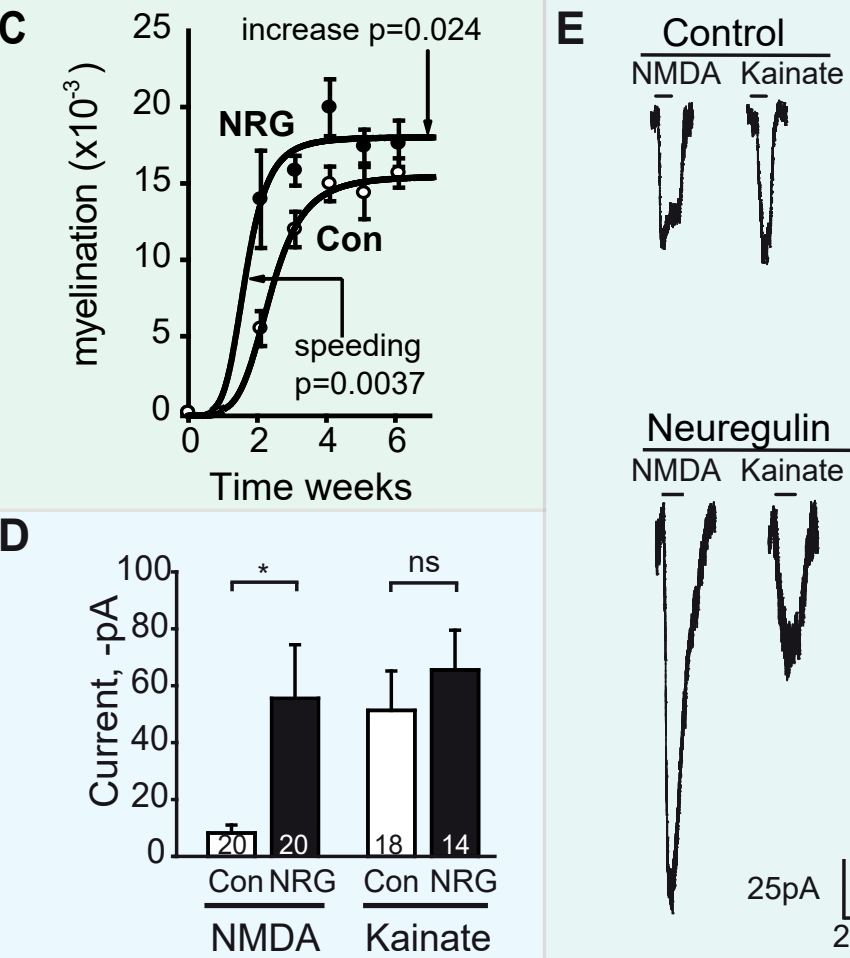

Neuregulin NMDA Kainate

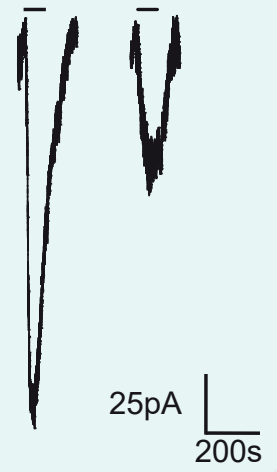

